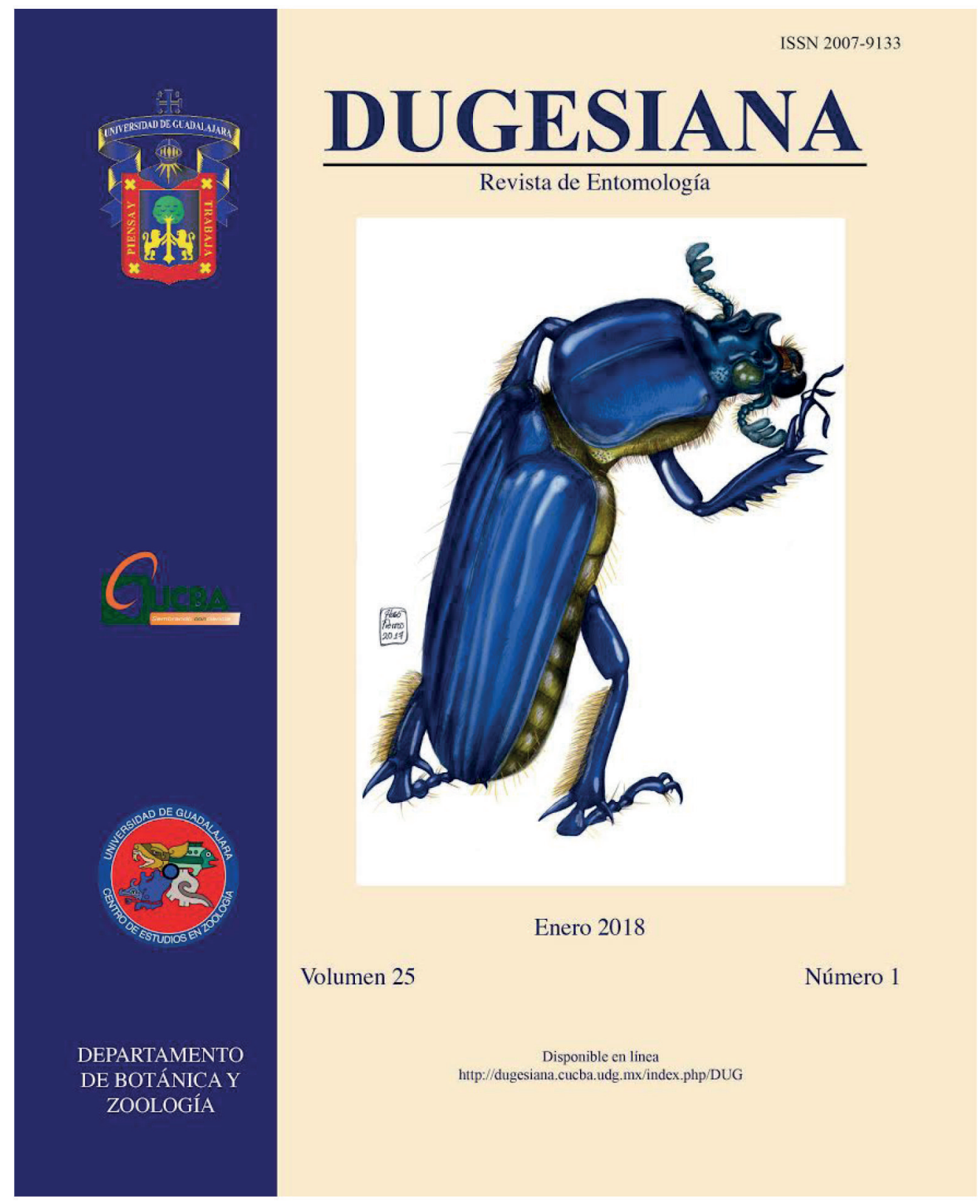

Dugesiana, Año 25, No. 1, enero 2018-junio 2018 (primer semestre de 2018), es una publicación Semestral, editada por la Universidad de Guadalajara, a través del Centro de Estudios en Zoología, por el Centro Universitario de Ciencias Biológicas y Agropecuarias. Camino Ramón Padilla Sánchez \# 2100, Nextipac, Zapopan, Jalisco, Tel. 37771150 ext. 33218, http://dugesiana.cucba.udg.mx/index.php/DUG, jose.navarrete@academicos.udg.mx. Editor responsable: José Luis Navarrete Heredia. Reserva de Derechos al Uso Exclusivo 04-2009-062310115100203, ISSN: 2007-9133, otorgados por el Instituto Nacional del Derecho de Autor. Responsable de la última actualización de este número: José Luis Navarrete Heredia, Editor y Ana Laura González-Hernández, Asistente Editorial. Fecha de la última modificación 1 de enero de 2018, con un tiraje de un ejemplar.

Las opiniones expresadas por los autores no necesariamente reflejan la postura del editor de la publicación.

Queda estrictamente prohibida la reproducción total o parcial de los contenidos e imágenes de la publicación sin previa autorización de la Universidad de Guadalajara. 


\title{
Revisión del grupo de especies "pruinosa" de Phyllophaga (Phytalus) (Coleoptera: Melolonthidae: Melolonthinae)
}

\section{Revision of the pruinosa group of Phyllophaga (Phytalus) (Coleoptera: Melolonthidae, Melolonthinae)}

\author{
Miguel Ángel Morón †* \\ Instituto de Ecología, A. C. Apdo. Postal 63, Xalapa, Veracruz 91000 México
}

\begin{abstract}
RESUMEN
Se actualiza el grupo "pruinosa" formado por seis especies mexicanas y centroamericanas: P. pruinosa (Blanchard, 1851) de Campeche, Chiapas, Hidalgo, Puebla, Oaxaca, San Luis Potosí, Tamaulipas y Veracruz, México; Rio San Juan, Nicaragua; Alajuela, Guanacaste, Heredia, Limón y San José, Costa Rica; P. tegulicolis Saylor, 1934 de Chiapas, México; Santa Rosa, Guatemala; Morazán y Tegucigalpa, Honduras; P. tegenera Saylor, 1935 de Carazo, Chinandega, Granada, Jinotega, Masaya y Rivas, Nicaragua; Guanacaste y Puntarenas, Costa Rica; P. hoogstraali Saylor, 1943 de Guerrero, Michoacán, Morelos y Puebla, México; P. tlilloa n. sp., de Colima, Guerrero, Jalisco, Estado de México, Morelos, Nayarit, Puebla y Sinaloa, México; y P. yautepecana n. sp., de Oaxaca, México. Se incluyen la diagnosis del grupo, las redescripciones de cuatro especies y las descripciones de dos especies nuevas, con ilustraciones de las estructuras diagnósticas, así como una clave para separar las especies del grupo.

Palabras clave: Melolontinos, taxonomía, nuevos registros, México, Centroamérica.
\end{abstract}

\begin{abstract}
The group "pruinosa" is updated, formed with six Mexican and Central American species: P. pruinosa (Blanchard, 1851) from Campeche, Chiapas, Hidalgo, Puebla, Oaxaca San Luis Potosí, Tamaulipas and Veracruz, Mexico; Rio San Juan, Nicaragua; and Alajuela, Guanacaste, Heredia, Limón and San Jose, Costa Rica; P. tegulicolis Saylor, 1934 from Chiapas, Mexico; Santa Rosa, Guatemala; Morazán and Tegucigalpa, Honduras; P. tegenera Saylor, 1935 from Carazo, Chinandega, Granada, Jinotega, Masaya and Rivas, Nicaragua; Guanacaste and Puntarenas, Costa Rica; P. hoogstraali Saylor, 1943 from Guerrero, Michoacan, Morelos and Puebla, Mexico; P. tlilloa n. sp., from Colima, Guerrero, Jalisco, State of Mexico, Morelos, Nayarit, Puebla and Sinaloa, Mexico; and P. yautepecana n. sp., from Oaxaca, Mexico. Diagnosis of the group, redescription of four species and descriptions of two new species with illustrations of diagnostic structures, and a key to separate species in this group is provided.
\end{abstract}

Key words: Chafers, taxonomy, new records, Mexico, Central America.

Los estudios realizados por Rivera-Gasperín y Morón (2013, 2017a, b) sobre la filogenia de Phyllophaga Harris, 1827 (sensu lato) han puesto en evidencia la necesidad de rectificar los niveles taxonómicos de los subgéneros y varios grupos de especies propuestos por Saylor (1942) y Morón (1986), que pueden definirse mejor por medio de nuevas combinaciones de caracteres morfológicos que incluyen sinapomorfías y apoyan su condición monofilética. El subgénero Phytalus Erichson, 1847 (s. lato) es uno de los agrupamientos que requiere más trabajo de reclasificación, sobre todo para incorporar correctamente las especies sudamericanas (Morón 2017).

Con apoyo en un análisis cladístico diseñado para distinguir agrupamientos supraespecíficos en el género Phyllophaga (s.l.) Morón (1986) propuso dividir en ocho grupos a las 43 especies del subgénero Phytalus hasta entonces descritas para Norte y Centro América. En el primero de estos grupos, denominado "pruinosa" se incluyeron cinco especies distribuidas entre Texas, EE. UU., y Nicaragua (Morón 1986), pero un análisis morfológico comparativo reciente indicó que tres de ellas no comparten todos los caracteres grupales de $P$. pruinosa Blanchard, 1851, mientras que las especies sudamericanas del grupo "puberea" muestran más similitud con el grupo "pruinosa" (Morón 2017).

Para continuar con los análisis comparativos de los grupos de especies mejor definidos, y como parte de las evidencias reunidas para revalidar la categoría genérica de Phytalus y describir nuevos géneros, a continuación se presenta una revisión del grupo "pruinosa", como una aportación al reordenamiento taxonómico de estos Melolonthini americanos.

\section{MATERIAL Y MÉTODOS}

Los términos morfológicos, los caracteres taxonómicos empleados y los criterios para valorar los rangos de

*Este trabajo fue enviado por el Dr. M.A. Morón el 13 de julio de 2017. El trabajo fue aceptado por los revisores justo un día previo a su lamentable deceso acaecido el 22 de agosto de 2017. La corrección del mismo estuvo a cargo del Dr. Pedro Reyes Castillo y del Biól. Pablo Antonio Martínez Rodríguez. Una pérdida importante para la entomología mexicana. 
variación específica, utilizados para las descripciones son los propuestos por Saylor (1942), Böving (1942), Sanderson (1958) y Morón (1986, 2003, 2006, 2013, 2017). Se utiliza el concepto de especie filogenética de Wheeler y Platnick (2000) donde las especies son las agrupaciones más pequeñas de poblaciones diagnosticables por una combinación única de estados de caracteres. Las ilustraciones se realizaron con ayuda de una cámara clara asociada a un estereomicroscopio Leica MZ8 empleando aumentos de 6.3 a $50 \mathrm{X}$, y con una videocámara acoplada a un estereomicroscopio Celestron 44206. Para las fotografías se utilizó un equipo Nikon D5200 provisto con un lente AF-S DX Micro Nikkor $40 \mathrm{~mm}$. Las medidas se obtuvieron con ayuda de un vernier electrónico y un micrómetro ocular acoplado al estereomicroscopio. Los ejemplares estudiados están depositados en las siguientes colecciones entomológicas:

American Museum of Natural History, New York (AMNH) Bruce D. Gill, Ottawa, Canada (BDGC)

CenAgro, Benemérita Universidad Autónoma de Puebla (BUAP)

California Academy of Sciences, San Francisco (CASC)

Canadian Museum of Nature, Ottawa (CMNC)

Canadian National Collection of Insects, Ottawa (CNCI)

Instituto de Biología, UNAM, Ciudad de México (CNIN)

Universidad de Guadalajara, Autlán, Jalisco (CUCsur)

Facultad de Estudios Superiores Zaragoza, UNAM, Ciudad de México (FESZ)

Florida State Collection of Arthropods, Gainesville (FSCA)

Instituto de Ecología, A.C. Xalapa, México (IEXA)

Natural History Museum of Los Angeles County, California (LACM)

Museo Entomológico de León, Nicaragua (MELN)

Museo Nacional de Costa Rica (MNCR)

Museum National d'Histoire Naturelle, Paris (MNHN)

Miguel A. Morón, Xalapa, México (MXAL)

National Museum of Natural History, Washington, D. C. (NMNH)

Texas A\&M University, College Station (TAMU)

Universidad del Valle de Guatemala (UVGC)

\section{Redescripción del grupo de especies "pruinosa"}

Cuerpo alargado, moderadamente robusto, con longitud de 15.5 a $21.0 \mathrm{~mm}$ y anchura humeral de $6.5 \mathrm{a}$ $9.8 \mathrm{~mm}$. Coloración parda oscura casi negra a parda rojiza, generalmente opaca a poco brillante. Vestidura setífera dorsal usualmente pruinosa grisácea a blanquecina, más o menos uniforme, en ocasiones con sedas erectas cortas esparcidas o restringidas a una región. Clípeo corto con los ángulos redondeados, y el borde anterior sinuado; superficie del disco irregular. Canthus ocular corto y estrecho. Vértice occipital ampliamente redondeado, poco prominente. Antenas con diez antenómeros, maza antenal formada por tres lamelas cubiertas con sensilas muy finas y sedas erectas cortas esparcidas. Labro bilobulado, prominente, ancho, con el borde anterior redondeado, profundamente escotado, con sedas erectas en los bordes. Disco del labio ligeramente cóncavo, con puntos someros y algunas sedas delgadas a los lados; el borde anterior ligeramente sinuado. Pronoto con bordes laterales ampliamente angulados, prominentes en su porción central; los márgenes laterales estrechos, lisos, crenulados o irregulares sobre todo en su mitad posterior, con un número variable de sedas erectas esparcidas; el margen anterior estrecho, marcado por un reborde poco prominente; el margen basal indicado por un surco somero en sus extremos laterales, y por puntos de diámetro y profundidad variable en toda su extensión. Élitros con los callos humerales prominentes y redondeados y los callos apicales amplios, redondeados, poco prominentes. Alas metatorácicas completamente desarrolladas. Vestidura del pterosternón blanquecina o amarillenta, larga y abundante. Protibias con tres procesos dentiformes en el borde externo, el intermedio poco más ancho y cercano al apical, el proceso proximal muy corto. Machos con el espolón protibial recto, delgado y aguzado, tan largo como el segundo tarsómero. Porción media de la cara externa de las mesotibias con una quilla setífera transversal oblicua completa y una prominencia setífera proximal. Espolón mesotibial externo o inferior alargado, con ápice aguzado, usualmente más corto que el espolón interior. Metatibias más cortas que los tarsos respectivos $(1,0: 1,3)$, con una carina setífera poco prominente en la mitad de la cara externa y un par de puntos setíferos proximales. Borde apical de las metatibias redondeado, con un lóbulo latero-inferior y con numerosas sedas espiniformes. Espolón metatibial interno o superior articulado, usualmente largo, con forma específica; espolón externo o inferior fusionado con el borde, muy largo o corto, con forma específica. Los tres protarsómeros proximales con accesorios subapicales con características específicas. Mesotarsómeros $1^{\circ}$ a $4^{\circ}$ con una hilera de sedas en sus regiones ventrales. Metatarsómeros $2^{\circ}$ a $4^{\circ}$, con dos hileras de sedas rígidas en su región ventral, y varias sedas largas periapicales. Machos con las uñas estrechamente hendidas, con el dentículo superior más estrecho y poco más corto que el inferior. El tegumento de los extremos laterales de los segmentos abdominales opaco o pruinoso, punteado, con cantidad variable de sedas; las suturas intersegmentales poco definidas en la porción mesial. Prepigidio amplio, opaco, con puntuación y vestidura variable. Placa pigidial amplia y convexa, poco prominente, con márgenes laterales estrechos y el margen basal ampliamente incompleto en su parte media. Parámeros fusionados entre sí dorsalmente, simétricos, poco deprimidos, con longitud variable, recurvados en diferentes proporciones específicas; sin prominencias latero-basales; porción ventral membranosa; la pieza basal generalmente es casi tan larga como los parámeros; tectum convexo o ligeramente excavado. Edeago sacular, membranoso, con accesorios de forma y proporciones específicas. Hembras muy parecidas a los machos, con la maza antenal más corta; uñas tarsales estrechamente hendidas; esternitos $2^{\circ}$ a $5^{\circ}$ convexos en su porción mesial; placa anal amplia, convexa; placa pigidial 
convexa o un poco prominente. Placas genitales superiores independientes entre sí.

Larva. No se conoce ningún estado inmaduro de las especies incluidas en el grupo.

Distribución: Noroeste y noreste de México hasta Costa Rica.

El grupo "pruinosa" propuesto por Morón (1986) se modificó retirando tres especies que carecen de vestidura pruinosa dorsal: P. trichodes (Bates) y P. sinaloana Saylor, tienen uñas tarsales hendidas con el dentículo inferior más corto y estrecho que el superior o apical; y P. prolixa (Bates) que presenta las uñas tarsales hendidas con el dentículo inferior más largo y ancho que el dentículo superior o apical, pero los parámeros son independientes en sus extremos apicales. Es posible que estas especies encabecen nuevos grupos, lo cual se espera resolver después de actualizar la filogenia de Phyllophaga (s. lato) (RiveraGasperín y Morón 2017b; Morón 2017). Las seis especies que forman el grupo "pruinosa" externamente comparten varios caracteres, pero muestran diferencias notables sobre todo en el extremo apical de las metatibias masculinas y en la configuración de las estructuras genitales.

\section{Clave para separar los machos de las especies del grupo "pruinosa"}

1 Pronoto y élitros sin sedas cortas erectas. Espolón metatibial inferior más corto que el espolón superior, o ensanchado y muy curvado .

1' Pronoto y élitros con sedas cortas erectas dispersas. Espolón metatibial inferior casi tan largo como el espolón superior, estrecho, casi recto o poco curvado

2. Márgenes laterales del pronoto moderadamente crenulados. Segundo protarsómero con una proyección laminar subapical (Fig. 58). Cuenca río Balsas, México ..... P. hoogstraali Saylor

2' Márgenes laterales del pronoto casi lisos. Segundo protarsómero sin proyección laminar subapical (Fig. 31). 3 3. Espolón metatibial inferior largo, muy curvado, con ápice ensanchado, redondeado (Fig. 50). Maza antenal más larga que los seis antenómeros precedentes. Cuenca alta río Tehuantepec, Oaxaca, México ........... P. yautepecana n. sp. 3' Espolón metatibial inferior corto, con ápice estrecho (Fig. 9). Maza antenal tan larga como los seis antenómeros precedentes

4. Espolón metatibial inferior ligeramente curvado o inclinado, con ápice redondeado (Fig. 19). Disco elitral ligeramente rugoso entre la puntuación. Parámeros alargados, con la mitad distal estrecha y recurvada ventralmente (Fig. 15). Vertiente del Golfo de México, Nicaragua y Costa Rica ............... P. pruinosa (Blanchard) 4' Espolón metatibial inferior recto o poco curvado, con un dentículo preapical lateral (Fig. 30). Disco elitral casi liso entre la puntuación. Parámeros alargados, con la mitad distal más ancha y menos recurvada que $P$. pruinosa (Fig. 37). Vertiente del Pacífico Mexicano y Cuenca del río Balsas P. tlilloa n. sp.
5. Parámeros alargados, esbeltos (Fig. 101) (cuatro veces más largos que anchos). Cuerpo esbelto, $14 \mathrm{~mm}$ longitud. Nicaragua y Costa Rica ......... P. tegenara Saylor 5' Parámeros alargados, robustos (Fig. 81) (tres veces más largos que anchos). Cuerpo robusto, $18 \mathrm{~mm}$ longitud. Chiapas, México y Honduras ............. P. tegulicolis Saylor

\section{Phyllophaga (Phytalus) pruinosa (Blanchard, 1851)}

(Figs. 1-20)

Phytalus pruinosus Blanchard, 1851. Catalogue collection entomologique: 131

Phytalus pruinosus Blanchard. Burmeister (1855: 351)

Phytalus pruinosus Blanchard. Gemminger \& Harold (1869: 1172)

Phytalus pruinosus Blanchard. Bates (1888: 177)

Phytalus pruinosus Blanchard. Dalla-Torre (1912: 217)

Phyllophaga pruinosa (Blanchard). Blackwelder (1944: 226)

Phyllophaga (Phytalus) pruinosa (Blanchard). Frey (1975: 222)

Phyllophaga (Phytalus) pruinosa (Blanchard). Morón (1986: 212)

Phyllophaga (Phytalus) pruinosa (Blanchard). Solís y Morón (1998: 22)

Phyllophaga pruinosa (Blanchard). Evans (2003: 142)

Redescripción: Machos. Longitud total del cuerpo: 17.8-19.5 mm. Anchura humeral: 7.8-8.2 mm. Relación longitud /anchura cuerpo: 2.3:1.0. Cabeza de color pardo oscuro casi negro a pardo rojizo oscuro, moderadamente brillante; pronoto pardo oscuro a pardo rojizo pruinoso a ligeramente brillante; élitros pardo oscuro a pardo rojizo con cubierta pruinosa densa, grisácea o blanquecina; patas de color pardo oscuro a rojizo brillante; abdomen pardo rojizo o amarillento, opaco, con extensa cubierta pruinosa ligera blanquecina (Figs. 1-2). Clípeo 2.8 veces más ancho que largo, redondeado, con el borde anterior claramente sinuado, un poco escotado, y los márgenes levantados; el disco clipeal glabro, poco convexo al centro y ligeramente cóncavo a los lados, con abundantes puntos amplios, someros. Sutura fronto-clipeal bien definida, notablemente sinuada (Fig. 8). Frente convexa 2.6 veces más ancha que larga, con puntos amplios, someros, irregularmente distribuidos, con escasas sedas cortas delgadas erectas. Tercer antenómero semicilíndrico, tan largo como el $4^{\circ} \mathrm{o}$ el $5^{\circ}$; antenómeros $6^{\circ}$ y $7^{\circ}$ más anchos que largos, cada uno con una proyección anterior aguzada corta. Maza antenal tan larga (1:1) como los seis antenómeros precedentes. La anchura dorsal de cada ojo es equivalente al $40 \%$ de la distancia interocular. Canthus ocular con 8-10 sedas erectas.

Pronoto 2.4 veces más ancho que largo; la relación anchura máxima de la cabeza-anchura máxima del pronoto es de 0.65:1.00 y la relación distancia interocular-anchura máxima del pronoto es de 0.42:1.00; superficie del disco pronotal uniformemente convexa, con vestidura pruinosa 
microscópica, con puntos redondos, bien definidos, poco profundos, irregularmente distribuidos, y algunas sedas cortas cerca de los bordes laterales; ángulos anteriores obtusos, poco prominentes; ángulos posteriores casi rectos, prominentes (Fig. 8). Escutelo poco más ancho que largo (1.2:1.0) casi liso, pruinoso, con 14-18 puntos redondos pequeños dispersos hacia cada lado. Élitros tres veces más largos que anchos, con superficie ligeramente rugosa $\mathrm{y}$ abundantes puntos redondos, pequeños, uniformemente distribuidos, algunos provistos con sedas blanquecinas diminutas; reborde de la epipleura estrecho, se extiende hasta el ápice y presenta sedas pequeñas erectas dispersas en toda su extensión. Segundo protarsómero con prominencia subapical pequeña y estrecha. Segundo mesotarsómero más largo que el tercer tarsómero (Fig. 11). Espolón metatibial superior o interno casi tan largo como el primer metatarsómero, ligeramente recurvado; espolón inferior o externo corto, ligeramente recurvado, con el ápice aguzado (Fig. 9). Segundo metatarsómero claramente más largo que el primero o el tercer tarsómero (Fig. 12). Todas las uñas tarsales con el dentículo inferior más largo y ancho que el dentículo apical (Fig. 10).

Los esternitos $2^{\circ}$ a $4^{\circ}$ ligeramente cóncavos en su parte mesial, con algunas sedas cortas esparcidas; el $5^{\circ}$ esternito con la parte media casi plana con algunas sedas cortas, y el borde posterior notablemente elevado. Placa anal corta, poco convexa, con gránulos dispersos, borde distal sencillo, ampliamente curvado, con escasas sedas periféricas. Prepigidio brillante con numerosos puntos pequeños regularmente dispuestos. Placa pigidial uniformemente convexa, brillante, punteada-rugosa irregular, con escasas sedas diminutas esparcidas; el margen apical estrecho, poco levantado, con 12 sedas largas erectas.

Parámeros fusionados basalmente, alargados, un poco deprimidos, muy recurvados ventralmente, con los extremos apicales parcialmente fusionados, paralelos, redondeados (Figs. 13-15); el saco interno predominantemente membranoso, con divertículos laterobasales y una proyección sacular dorsal preapical, cubierta con abundantes micro espinas (Figs. 15, 18). Longitud del edeago desde el ápice de los parámeros al extremo de la pieza basal: $5.0-5.5 \mathrm{~mm}$.

Hembra. Similar al macho (Figs. 3-7) excepto: longitud corporal 18.0-19.8 mm, anchura humeral 7.7-8.4 mm. Maza antenal tan larga como los 5 antenómeros precedentes. Élitros con algunas sedas muy cortas esparcidas cerca de los bordes laterales y en el extremo apical. Espolones metatibiales alargados, ensanchados, poco recurvados, el inferior más corto, con ápice redondeado, el superior con ápice ligeramente agudo (Fig. 16). Esternitos convexos casi lisos, con escasas sedas muy cortas dispersas; placa anal corta, convexa, con puntos irregulares y algunas sedas erectas. Placa pigidial convexa, progresivamente prominente hacia el ápice, con puntuación irregular y algunas sedas cortas esparcidas; márgenes latero apicales bien definidos. Placas genitales inferiores esclerosadas, redondeadas, ligeramente asimétricas, poco convexas, con algunas sedas largas cerca del borde apical; placas genitales superiores pequeñas, ovaladas, con pocas sedas apicales (Fig. 17).

Variación. Longitud corporal 17.8-19.8 mm; anchura humeral 7.7-8.4 mm; el color del pronoto y élitros puede ser pardo rojizo oscuro a pardo oscuro casi negro. La cobertura pruinosa dorsal usualmente es intensa excepto en ejemplares con muestras de abrasión cuticular. La longitud y anchura del espolón metatibial exterior o inferior varía ligeramente en ejemplares de diferente procedencia (Figs. 9, 19). La curvatura y anchura de los parámeros varían ligeramente en muestras de localidades distintas (Figs. 13, $15,18,20)$.

Distribución. Oriente y sureste de México, sur de Nicaragua y Costa Rica (Fig. 108).

Ejemplares examinados. 239 (158 machos, 81 hembras). Lectotipo hembra Phytalus pruinosus, aquí designado, etiquetado: "Mexique, Giesbreight" / "42" / "P. pruinosus, Cat. Mus. Mexique M. Giesbreight" / "SYNTYPE" / "MNHN EC 8136" / "Lectotype Phytalus pruinosus Blanchard, M. A. Morón det. 2017" (MNHN). COSTA RICA: Alajuela, Sector Colonia Palmarena, 9 Km SO Bajo Rodríguez, 700m, III-1996, G. Carballo (2); mismos datos excepto: 22-IV-1995, E. Fletes (1); IV1995, G. Carballo (1); Guatuso, P.N. Volcán Tenorio, Valle Río Buenavista, Teñideros, 800-900m, 24-II-2012, J. A. Azofeifa (1). Guanacaste, Z. P. Tenorio, Rio San Lorenzo, 1050 m, Tierras Morenas, IV-1991, C. Alvarado (1); mismos datos excepto: 21-IV-1992, A. Marín (9); IV-1992, F. Quezada (2); IV-1992, C. Alvarado (1); 23-III-1992, M. Segura (6); Tilaran, V-1994, G. Rodríguez (1). Heredia, Las Horquetas de Sarapiquí, El Plástico, 700m, 29-IV1991, J. E. Solano (1); Z.P. La Selva, Estación El Ceibo, 400 - 500m, 12-III-2003, A. Solís (2); Est. Magsasay, P. N. Braulio Carrillo, 200 m, II-1991, A. Fernández (1); Sarapiquí. Z.P. La Selva. Est. Biol. La Selva, 50-150m, 13-IV-1993, D. Brenes (1); mismos datos excepto: 16III-1999 (1). Limón, Amubri, A.C. Amistad., 70 m, 2-V1994, G. Gallardo (1); mismos datos excepto: 3-IV-1995, A. M. Mora (1); 8-III-1994, G. Gallardo (1). P.N. Braulio Carrillo, Quebrada González, 500-600m. 1-III-2006, J. A. Azofeifa (2); Sector Cedrales de la Rita, $3 \mathrm{Km} \mathrm{N}$. del Puente Rio Suerte, Ruta Puerto Lindo, 10m, III-1996. E. Rojas (1); Cuatro Esquinas, P. N. Tortuguero, 0m, IV1989, R. Aguilar (11); Rio Sardinas, R.N.F.S. Barra del Colorado, 10m, 16-III-1994, F. Araya (1); mismos datos excepto: 6-IV-1994 (1). San José, P. N. Braulio Carrillo, 700 m, 20-II-1983, I. Chacón (1) (33 machos, 17 hembras MNCR); Estación Carrillo, 750m, 28-III-1987, A. Solís (1 MXAL). MEXICO: Campeche, Escárcega, 24-V-1959, T. C. Emmel (1, LACM). Chiapas, $16 \mathrm{~km}$ W Ocozocoautla, Laguna Bélgica, 970m, 13-VI-1990, H. y A. Howden (1, CMNC); 2 km S Chicoasen Rd. to Mirador, 15-VI-1989, H.F. Howden (1,CMNC); 5 mi SW El Bosque, 10-VI1969, J.M. Campbell (6,CNCI); 2 mi S Simojovel, 9-VI- 
1969, J.M. Campbell (7,CNCI); Palenque, 22-VI-1969, D. Bright y J.M. Campbell (3, CNCI); mismos datos excepto: 7-V-1969(1, CNCI); 10 mi S Malpaso, 24-V-1969, J. M. Campbell (1, CNCI); El Bosque, desv. La Trinidad, 17-VI1983, M.A. Morón, J. Valenzuela y M. Pérez (1, MXAL); $0.5 \mathrm{~km}$ N Parque Laguna Bélgica, 23-VI-1990, M.C. Thomas (9, FSCA); Parque Laguna Bélgica, 27-V-1987, D.A. Rider y E.G. Riley (11, EGRC); Boca Lacantún, 24-V1984, M. García (1, CNIN). Hidalgo, Tepehuacan, Cañada Otongo, 850 m, 1-VI-1981, M.A. Morón (1); mismos datos excepto: $1050 \mathrm{~m}, 1$-VII-1981(1); $1070 \mathrm{~m}, 1-\mathrm{VI}-1981 \mathrm{R}$. Terrón (2); 1300 m, 26-V-1979 (1); 1022 m, 12-VII-1980 (1); 750 m, 23-VI-1979 (1); Molango, Acuatitlán, 1535 m, 21-VII-1979, M.A. Morón (1); Ixtlahuaco, 1650 m, 16-VI1980, R. Terrón (1); Tlanchinol, 1500 m, 6-VI-1996, G. Nogueira (1) (MXAL). Oaxaca, km 140 Hwy 175 Oaxaca, 4000', 22-V-1969, H.F. Howden (1, CNCI); 15 mi S Valle Nacional, 1330m, 20-V-1971, H.F. Howden (1, CMNC); 6 mi S Valle Nacional, 660m, 18-V-1971, D. Bright (1, CNCI); 15 mi S Valle Nacional, 1330m, 20-V-1971, D. Bright (1, CNCI); Sierra de Juárez, Metates, 24-V-1982, L. González-Cota (1, MXAL); Sierra de Juárez, Comaltepec, 1700m, 21-V-1996, G. Nogueira (1, MXAL); El Tule, 29-VII-1969, L. A. Kelton (1, CNCI); 22.4 mi N Puerto Escondido, 700m, 20-VII-1966, G. Ball y D. Whitehead (1,CNCI). Puebla, Villa Juárez, 22-V-1963, C. O. Morse (1, CMNC); Xicotepec de Juárez, 1200 m, 28-V-1977, T. Zoebisch (2, MXAL); Cuetzalan, IV-1998 (14), V-1998 (3), VI-1998 (3) H. Carrillo (IEXA, BUAP). San Luis Potosí, Tamazunchale, 20-V-1952, M. Cazier (1, AMNH); Maguey de Oriente, $865 \mathrm{~m}$, 7-VIII-2003, G. Nogueira (1, MXAL). Tamaulipas, Bocatoma, 7 km SSE Gómez Farías, 27-V-1979, E.G. Riley (2, EGRC). Veracruz, Fortín de las Flores, 24-V-1963, C. O. Morse (1, CMNC); mismos datos excepto: 8-VI-1964 (2,CNCI); 25-VI-1963, R. E. Woodruff (7, FSCA); 6-V-1964 (2, FSCA); Fortín de Las Flores, Metlac, 16-V-1964, R. E. Woodruff (2, FSCA); Paso del Macho, Rancho Canaletas, $550 \mathrm{~m}$, bosque trop perennifolio, 1-VI-2008, S. Rivera-Gasperín (2, BUAP); mismos datos excepto: $490 \mathrm{~m}, 1-\mathrm{V} / 2008$ (1 BUAP); Coatepec, 1300m, 3-VI-2007, T. Suárez (1, MXAL); Coatepec, Briones, 1450 m, 25-VI-1997, M.A. Morón (1); mismos datos excepto: 27-V-1998 (1); 29-V-2013 (1); 2-VI-2016 (1) (MXAL); $1 \mathrm{~km}$ W Briones, JBT, 1350m, 16-V-2000 (1); 17-V-2000 (4); 19-V-2000 (19); 20-V-2000 (2); 21-V-2000 (6); 22-V2000 (5); 23-V-2000 (7); 24-V-2000 (5); 25-V-2000 (1); 26-V-2000 (12); 27-V-2000 (2); 29-V-2000 (5); 1-VI-2000 (1); 17-VI-2000 (12); 18-VI-2000 (4); 22-VI-2000 (1); 23 VI-2000 (1); 30-VI-2000 (2)(IEXA); Jalapa, 22-V-1946, J. D. Pallister (4,AMNH); Xalapa, km 2.5 carr. antigua a Coatepec, 18-V-1989, L. Pérez (1, MXAL); 5-VI-2003, J. Valenzuela (1, MXAL); Xalapa, 1350 m, 2-V-1995, V. Hernández (2, MXAL). NICARAGUA: Río San Juan: Reserva Biosfera Indio Maíz: Dos Bocas de Río Indio, 5-II2006, J. Maradiaga y R. Muñoz (2); mismos datos excepto: 28-II-2006, P. Sandoval y E. Basquez (5); 16-II-2007, E.
Lunbi (4); 15-III-2007, P. Sandoval (5); Rio Indio, Camp 2, 50 m, 18-IV-2004, M. Torrez (1); Rio Indio: Camp 3, 50 m, 22-IV-2004, M. Torrez (1). Rio Indio: campamento 12, 21 VI-2004, M. Torres (1); Sarapiquí, 5-III-2006, P. D. Andino (1); mismos datos excepto: 1-IV-2006 (2); 16-III-2007, A. Borges (2); 15-III-2007, (1); 1-IV-2008, J. L. Pichardo (6) (MELN).

Datos biológicos. Habita en ambientes templados, semicálidos y cálidos, húmedos, situados entre el nivel del mar y $1700 \mathrm{~m}$ de altitud, originalmente ocupados por bosques tropicales perennifolios o bosques mesófilos de montaña y plantaciones diversas. Es una especie moderadamente abundante, la fenología de los adultos varía ligeramente entre México y América Central: en México se han capturado durante abril (14), mayo (117), junio (73), julio (5) y agosto (1); en Nicaragua durante febrero (6), marzo (14), abril (30), mayo (1); en Costa Rica durante febrero (3), marzo (17), abril (30) y mayo (1). Ocasionalmente los adultos acuden a las luces eléctricas, se les ha observado sobre follaje y flores de Hibiscus rosa-sinensis L. (Malvaceae), y son atraídos por esencias vegetales sintéticas (Morón 1996 y obs. pers.). Se desconocen sus larvas.

Comentarios. Phytalus pruinosa se ha citado erróneamente de Brasil (Dalla-Torre 1912; Blackwelder 1944; Evans 2003) tal vez confundido con P. puberea Mannerheim, como fue señalado por Frey (1975). Ambas especies tienen algunos caracteres en común además del aspecto oscuro y pruinoso, pero el cuerpo de $P$. pruinosa es más pequeño y esbelto en comparación con $P$. puberea, y los parámeros de $P$. pruinosa carecen de proyecciones laterobasales (Morón 2017).

\section{Phyllophaga (Phytalus) tlilloa sp. nov. (Figs. 21-24, 29-46) \\ http://zoobank.org/ C545D7BE-C940-4529-94E5- 1BC0853DF63A}

Descripción: Macho. Longitud total del cuerpo: 16.4 $\mathrm{mm}$. Anchura humeral: $7.5 \mathrm{~mm}$. Relación longitud / anchura cuerpo: 2.2:1.0. Cabeza de color pardo oscuro rojizo, brillante; pronoto y élitros pardo rojizo con cubierta pruinosa fina, grisácea iridiscente; patas de color pardo rojizo brillante; abdomen pardo rojizo, opaco, con extensa cubierta pruinosa fina blanquecina (Figs. 21-22). Clípeo 2.6 veces más ancho que largo, redondeado, con el borde anterior ligeramente sinuado y los márgenes poco levantados; el disco clipeal glabro, poco convexo al centro y ligeramente cóncavo a los lados, con abundantes puntos circulares, irregulares. Sutura fronto-clipeal bien definida, sinuada (Fig. 29). Frente convexa 2.5 veces más ancha que larga, con puntos amplios, irregularmente distribuidos, con escasas sedas cortas delgadas erectas cerca de los ojos. Tercer antenómero semicilíndrico, más corto que los antenómeros $4^{\circ}$ o el $5^{\circ}$, que son más gruesos, con ligeras protuberancias en su lado anterior; antenómeros $6^{\circ}$ y $7^{\circ}$ más anchos que largos, cada uno con una proyección anterior 
aguzada corta. Maza antenal tan larga (1:1) como los seis antenómeros precedentes. La anchura dorsal de cada ojo es equivalente al $40 \%$ de la distancia interocular. Canthus ocular con 11 sedas erectas.

Pronoto 2.4 veces más ancho que largo; la relación anchura máxima de la cabeza-anchura máxima del pronoto es de 0.65:1.00 y la relación distancia interocular-anchura máxima del pronoto es de 0.40:1.00; superficie del disco pronotal uniformemente convexa, con vestidura pruinosa microscópica, puntos redondos, bien definidos, poco profundos, irregularmente distribuidos, sin sedas; ángulos anteriores obtusos, prominentes; ángulos posteriores obtusos, prominentes (Fig. 29). Escutelo poco más ancho que largo (1.2:1.0) casi liso, pruinoso, con 12 puntos redondos pequeños dispersos hacia cada lado. Élitros 3 veces más largos que anchos, con superficie casi lisa y abundantes puntos redondos, pequeños, uniformemente distribuidos, sin sedas diminutas; reborde de la epipleura estrecho, se extiende hasta el ápice y presenta sedas pequeñas erectas dispersas en toda su extensión. Segundo protarsómero con prominencia subapical pequeña y estrecha (Fig. 31). Segundo mesotarsómero más largo que el tercer tarsómero (Fig. 32). Espolón metatibial superior o interno casi tan largo como el primer metatarsómero, ligeramente recurvado con ápice estrecho; espolón inferior o externo corto, con un dentículo preapical (Fig. 30). Segundo metatarsómero claramente más largo que el primero o el tercer tarsómero (Fig. 33). Todas las uñas tarsales con el dentículo inferior más largo y ancho que el dentículo apical (Fig. 34).

Los esternitos $2^{\circ}$ a $4^{\circ}$ ligeramente planos en su parte mesial, con algunas sedas cortas esparcidas; el $5^{\circ}$ esternito con la parte media poco convexa con algunas sedas cortas, y el borde posterior ligeramente elevado. Placa anal corta, poco convexa, con puntos y sedas dispersas, borde distal sencillo, ampliamente curvado, con escasas sedas periféricas. Prepigidio pruinoso con numerosos puntos pequeños regularmente dispuestos. Placa pigidial uniformemente convexa, pruinosa, con puntos circulares y sedas muy cortas regularmente dispuestas; el margen apical estrecho, poco levantado, con 16 sedas largas erectas.

Parámeros fusionados basalmente, alargados, un poco deprimidos, recurvados ventralmente, con los extremos apicales parcialmente fusionados, paralelos, redondeados (Figs. 35-37); el saco interno predominantemente membranoso, con soporte esclerosado y el extremo apical cubierto con micro espinas (Fig. 37). Longitud del edeago desde el ápice de los parámeros al extremo de la pieza basal: $5.1 \mathrm{~mm}$.

Hembra. Similar al macho (Figs. 23-24) excepto: longitud corporal $16.6 \mathrm{~mm}$, anchura humeral $7.7 \mathrm{~mm}$. Maza antenal poco más larga que los 5 antenómeros precedentes. Élitros con algunas sedas muy cortas esparcidas cerca del extremo apical. Espolones metatibiales alargados, ensanchados, recurvados, el inferior ligeramente más corto, ambos con ápice redondeado (Fig. 38). Esternitos convexos con escasas sedas muy cortas dispersas; placa anal corta, convexa, con puntos irregulares y algunas sedas erectas. Placa pigidial convexa, con puntuación circular amplia, somera, irregularmente dispuesta al centro del disco y progresivamente rugosa hacia los extremos apical y basal, los puntos tienen sedas cortas erectas; márgenes latero apicales estrechos, bien definidos. Placas genitales inferiores esclerosadas, alargadas, ligeramente asimétricas, poco convexas, con pocas sedas cerca del borde apical; placas genitales superiores pequeñas, semi-ovaladas, con pocas sedas apicales (Fig. 39).

Variación. Longitud corporal 16.0-18.8 mm; anchura humeral 7.1-8.4 mm; el color del pronoto y élitros puede ser pardo oscuro a pardo rojizo. La cobertura pruinosa dorsal es uniforme y varía poco la intensidad de su iridiscencia. En algunos machos de la parte alta de la Cuenca del Balsas los meso y metatarsómeros son un poco más largos o estrechos (Figs. 42-43) y la curvatura de las uñas tarsales es más acentuada (Fig. 40). El tamaño y la forma del espolón metatibial inferior varía un poco en ejemplares de diferente procedencia (Figs. 30, 41). La curvatura y anchura de los parámeros es ligeramente diferente en muestras de localidades distintas (Figs. 44-46).

Distribución. Vertiente del Pacífico y cuenca del Río Balsas, México (Fig. 108).

Ejemplares examinados. 131 (57 machos, 74 hembras). Holotipo macho etiquetado: MEXICO: Nayarit, Tepic, El Refugio, 990 m, 1-VII-1994, M. A. Morón (MXAL). Alotipo hembra: mismos datos que el holotipo (MXAL). Paratipos (129): MEXICO: Colima, Comala, 700 m, 30-VI-2000, G. Nogueira (1); 8-VII-2000 (1) (MXAL). Guerrero, Cacahuamilpa, 750 m, 9-VI-2004, M. Ordoñez (1); Acuitlapán, El Oyanco, 800 m, 25-VII2004, M. Ordoñez (1) (FESZ); km 102 carr Cd AltamiranoZihuatanejo Rt 134, 1300m, 22.VI-1990, E. Barrera (1); Acahuizotla, VI-1983 (3); VII-1983 (2); VIII-1983 (1), A. Díaz (1) (CNIN). Jalisco, Ameca, Sierra del Águila, 1518m, 31-V-2014, E. Colima (2) (CUCsur); Ameca, 29VI-1984, F. Pérez (1); Estación Chamela, 13-VI-1986, A. Usela (1) (MXAL); mismos datos excepto: 24-VI-1990, F. A. Noguera (2) (CNIN). México, Tejupilco, Pueblo Nuevo, 909 m, 18-VII-2004, M. Ordoñez (1) (FESZ). Morelos, 5.1 mi E Cuernavaca, 1660 m, 29-VI-1973, M. E. Murray (1); $5.1 \mathrm{mi}$ E Cuernavaca, 1660m, 29-VI-1973, R. R. Murray (1) (TAMU); Acamilpa, VII-1994, R. Arce (1) (IEXA). Nayarit, Tepic, 28-VII-1953, C. y P. Vaurie (8) (AMNH); Tepic, Colonia Moderna, 900 m, 11-VII-1995, A. Ramírez (1); Tepic, El Refugio, 990 m, 1-VII-1994, S. Hernández y M. A. Morón (4) (MXAL); 9 mi N Compostela, 20-VII1963, R. L. Westcott (2); Compostela, C. Papp (3) (LACM); Compostela, Miravalles, 870 m, 4-VII-1994, S. Hernández (1); El Venado, 50 m, 20-VII-1998, G. Nogueira (2) (MXAL); San Blas, 5-VII-1972, K. Stephan (5) (FSCA); 6 mi NE San Blas, 21-VII-1963, R. L. Westcott (12 LACM, MXAL); Rio Santiago, El Nayar, 15-VII-1991, E. Barrera (1) (CNIN); Santa María del Oro, 1000 m, luz, 22-VII-1993, 
G. Nogueira (2); Volcán Tepetiltic, 1200m, 9-VIII-2008, G. Nogueira (4) (MXAL). Puebla, Chiautla de Tapia, V-2006 (3), VII-2006, V.A. Cuate (12) (IEXA, BUAP); Chiautla, San Miguel, La Cantera, 1082m, 6-VII-2005, R. Avelleira (4) (MXAL). Sinaloa, 27 mi E Villa Unión, 7-VII-1964, H. F. Howden (28); 28 mi E Villa Unión, 4-VII-1964, J. E. H. Martin (20); 28 mi W El Palmito, 6.VII-1964, H. F. Howden (1) (CNCI).

Datos biológicos. Habita en ambientes semicálidos y cálidos, húmedos o subhúmedos, situados entre los $50 \mathrm{y}$ $1660 \mathrm{~m}$ de altitud, originalmente ocupados por bosques tropicales caducifolios o subcaducifolios, encinares, huertos o plantaciones diversas. Es una especie poco abundante, con frecuencia los adultos acuden a las luces eléctricas durante mayo (5), junio (12), julio (109) y agosto (5), y se les ha observado sobre follaje de Guazuma ulmifolia Lam. (Sterculiaceae). Se desconocen sus larvas.

Etimología. El nombre específico tlilloa es una adaptación de los términos de la lengua náhuatl: tlileua, tlileuac, tliltic, tlilloa, ennegrecido, teñido de negro, oscuro, moreno (Simeón 1977) en referencia a su coloración corporal.

Comentarios. Hasta ahora los individuos de esta especie capturados en localidades de la vertiente del Pacífico mexicano fueron asignados a $P$. pruinosa, pero en realidad corresponden a un taxón inédito, adaptado a las condiciones más cálidas y secas de esas regiones y en los ambientes que bordean al río Balsas y afluentes. Ambas especies tienen varios caracteres en común además del aspecto mate oscuro, pero en comparación con P. pruinosa, el cuerpo de $P$. tlilloa es esbelto, las superficies elitral y pigidial son más lisas, el espolón metatibial inferior muestra un dentículo, y los parámeros son más cortos y menos recurvados.

\section{Phyllophaga (Phytalus) yautepecana sp. nov. (Figs. 25-28, 47-56) \\ http://zoobank.org/ 195E33BB-0EC6-4ED1-86A2- E49A9376824A}

Descripción: Macho. Longitud total del cuerpo: 15.4 $\mathrm{mm}$. Anchura humeral: $6.7 \mathrm{~mm}$. Relación longitud / anchura cuerpo: 2.3:1.0. Cabeza de color pardo oscuro rojizo, brillante; pronoto pardo rojizo con cubierta pruinosa grisácea, élitros pardo rojizo-amarillento con cubierta pruinosa fina, grisácea; patas de color pardo rojizo brillante; abdomen pardo amarillento, brillante, con escasa pruinosidad blanquecina hacia los lados (Figs. 25-26). Clípeo 2.6 veces más ancho que largo, redondeado, con el borde anterior ligeramente sinuado y los márgenes levantados; el disco clipeal glabro, poco convexo al centro y ligeramente cóncavo a los lados, con puntos circulares, estrechos, profundos, irregularmente distribuidos. Sutura fronto-clipeal bien definida, sinuada (Fig. 47). Frente convexa 2.5 veces más ancha que larga, con puntos circulares, estrechos, irregularmente distribuidos, con escasas sedas cortas erectas cerca de los ojos. Tercer antenómero semicilíndrico, tan largo como los antenómeros $4^{\circ}$ o $5^{\circ}$, que son poco más gruesos, con ligeras protuberancias en su lado anterior; antenómeros $6^{\circ}$ y $7^{\circ}$ más anchos que largos, cada uno con una proyección anterior aguzada corta. Maza antenal más larga (1.3:1.0) que los seis antenómeros precedentes. La anchura dorsal de cada ojo es equivalente al $46 \%$ de la distancia interocular. Canthus ocular con 12 sedas erectas.

Pronoto 2.5 veces más ancho que largo; la relación anchura máxima de la cabeza-anchura máxima del pronoto es de 0.70:1.00 y la relación distancia interocularanchura máxima del pronoto es de 0.40:1.00; superficie del disco pronotal uniformemente convexa, con vestidura pruinosa microscópica, puntos redondos pequeños, bien definidos, poco profundos, irregularmente distribuidos, sin sedas; ángulos anteriores obtusos, prominentes; ángulos posteriores obtusos, poco prominentes (Fig. 47). Escutelo poco más ancho que largo (1.2:1.0) casi liso, pruinoso, con 18 puntos redondos muy pequeños dispersos hacia cada lado. Élitros 3 veces más largos que anchos, con superficie casi lisa y abundantes puntos redondos, pequeños, uniformemente distribuidos, sin sedas diminutas; reborde de la epipleura estrecho, se extiende hasta el ápice y presenta sedas pequeñas erectas regularmente dispuestas en toda su extensión. Segundo protarsómero con prominencia subapical pequeña y estrecha. Segundo mesotarsómero poco más largo que el tercer tarsómero (Fig. 49). Espolón metatibial superior o interno casi tan largo como el primer metatarsómero, ligeramente recurvado con ápice redondeado; espolón inferior o externo alargado, muy recurvado, ensanchado hacia el ápice redondeado (Fig. 50). Segundo metatarsómero claramente más largo que el primero o el tercer tarsómero (Fig. 51). Todas las uñas tarsales con el dentículo inferior más largo y ancho que el dentículo apical (Fig. 48).

Los esternitos $2^{\circ}$ a $4^{\circ}$ ligeramente excavados en su parte mesial, con pocas sedas cortas esparcidas; el $5^{\circ}$ esternito con la parte media ligeramente prominente con algunos puntos setíferos, y el borde posterior en ligero declive. Placa anal corta, poco convexa, con puntos y sedas dispersas, borde distal levantado, ampliamente curvado, con escasas sedas periféricas. Prepigidio semiopaco, poco pruinoso con numerosos puntos setíferos pequeños regularmente dispuestos. Placa pigidial uniformemente convexa, brillante, con puntos irregulares someros sin sedas; el margen apical estrecho, poco levantado, con ocho sedas erectas.

Parámeros fusionados basalmente, alargados, un poco deprimidos, recurvados ventralmente, con los extremos apicales independientes, paralelos, redondeados (Figs. 52-54); el saco interno predominantemente membranoso, con soporte esclerosado y el extremo apical cubierto con micro espinas. Longitud del edeago desde el ápice de los parámeros al extremo de la pieza basal: $3.3 \mathrm{~mm}$.

Hembra. Similar al macho (Figs. 27-28) excepto: longitud corporal $17.6 \mathrm{~mm}$, anchura humeral $6.7 \mathrm{~mm}$. Maza 
antenal poco más larga (1.2:1.0) que los cinco antenómeros precedentes. Pronoto y élitros con vestidura pruinosa difusa, sin sedas cortas esparcidas. Espolones metatibiales alargados, ensanchados, recurvados, el inferior ligeramente más corto y ancho, ambos con ápice redondeado (Fig. 55). Esternitos convexos con escasas sedas muy cortas dispersas; placa anal corta, convexa, con puntos irregulares $\mathrm{y}$ algunas sedas erectas. Placa pigidial convexa, glabra, con puntuación circular profunda, regularmente dispuesta en casi todo el disco, excepto cerca del ápice, margen apical poco más ancho que los márgenes laterales. Placas genitales inferiores esclerosadas, alargadas, ligeramente asimétricas, poco convexas, con pocas sedas cerca del borde apical; placas genitales superiores pequeñas, romboidales, con pocas sedas apicales (Fig. 56).

Variación. Longitud corporal 15.4-17.6 mm; anchura humeral 6.7-6.8 $\mathrm{mm}$; el color del pronoto y élitros puede ser pardo oscuro rojizo a pardo amarillento rojizo.

Distribución. Región de Yautepec, Oaxaca, México (Fig. 109).

Ejemplares examinados. 5 ejemplares $(3$ machos, 2 hembras). Holotipo macho etiquetado: MEXICO: Oaxaca, 5 mi W El Camarón, 20-V-1969, H. F. Howden (CNCI. Mismos datos que el holotipo: alotipo hembra (MXAL), paratipo macho (CNCI), paratipo macho (MXAL). Paratipo hembra: MEXICO: Oaxaca, 2.7 mi NW El Camarón, 24VII-1972, Mastro \& Schaffner (MXAL).

Datos biológicos. Habita en ambientes cálidos, subhúmedos, situados entre los 800 y $900 \mathrm{~m}$ de altitud, originalmente ocupados por bosques tropicales caducifolios, encinares poco húmedos o matorrales xerófilos. Es una especie poco abundante, los adultos han sido atraídos a las luces eléctricas durante mayo (4) y julio (1). Se desconocen sus hábitos y larvas.

Etimología. El nombre específico procede del locativo Yauhtepec, que en lengua náhuatl está formado por los vocablos: yauitl, maíz negro, y tépetl, montaña (Simeón 1977) en referencia a la región montañosa de San Carlos Yautepec, Oaxaca, donde se obtuvo la serie típica.

Comentarios. Esta especie se distingue de $P$. pruinosa y $P$. tlilloa por la forma del espolón metatibial masculino alargado y recurvado, las proporciones de los parámeros, la maza antenal del macho poco más larga que los seis antenómeros precedentes, y la cubierta pruinosa del cuerpo poco densa.

\section{Phyllophaga (Phytalus) hoogstraali Saylor, 1943} (Figs. 57-71)

Phyllophaga (Phytalus) hoogstraali Saylor, 1943. Proc. Biol. Soc. Washington 56: 21

Phyllophaga (Phytalus) hoogstraali Saylor. Morón (1986: 212)

Phyllophaga hoogstraali Saylor. Evans (2003: 109)

Redescripción: Machos. Longitud total del cuerpo: 17.0-20.8 mm. Anchura humeral: 9.5-11.4 mm. Relación longitud /anchura cuerpo: 1.9:1.0. Cabeza de color pardo oscuro negruzco brillante; pronoto pardo oscuro a pardo rojizo pruinoso; élitros pardo rojizo con cubierta pruinosa blanquecina; patas de color pardo oscuro a rojizo brillante; abdomen pardo amarillento, opaco, con cubierta pruinosa ligera blanquecina (Figs. 68-69). Clípeo 2.4 veces más ancho que largo, redondeado, con el borde anterior ligeramente sinuado y los márgenes levantados; el disco clipeal poco convexo al centro y ligeramente cóncavo a los lados, con puntuación ligeramente rugosa, somera, y algunas sedas diminutas. Sutura fronto-clipeal bien definida, poco sinuada (Fig. 57). Frente convexa 2.3 veces más ancha que larga, con puntuación rugosa, irregularmente distribuida y abundantes sedas delgadas erectas. Tercer antenómero semicilíndrico, poco más corto que el $4^{\circ}$ o el $5^{\circ}$ que muestran ligeras prominencias anteriores; antenómeros $6^{\circ}$ y $7^{\circ}$ más anchos que largos, cada uno con una proyección anterior aguzada corta. Maza antenal tan larga (1:1) como los seis antenómeros precedentes. La anchura dorsal de cada ojo es equivalente al $32 \%$ de la distancia interocular. Canthus ocular con 9-12 sedas erectas.

Pronoto 2.3 veces más ancho que largo; la relación anchura máxima de la cabeza-anchura máxima del pronoto es de 0.60:1.00 y la relación distancia interocular-anchura máxima del pronoto es de 0.48:1.00; superficie del disco pronotal uniformemente convexa, con vestidura pruinosa microscópica, con puntos redondos, bien definidos, profundos, irregularmente distribuidos, sin sedas macroscópicas; márgenes laterales claramente crenulados en toda su extensión; ángulos anteriores un poco obtusos, prominentes; ángulos posteriores obtusos, prominentes (Fig. 57). Escutelo más ancho que largo (1.4:1.0) casi liso, pruinoso, con 10-12 puntos redondos pequeños dispersos hacia cada lado. Élitros 2.8 veces más largos que anchos, con superficie ligeramente rugosa y abundantes puntos redondos, irregulares, uniformemente distribuidos, sin sedas macroscópicas; reborde de la epipleura estrecho, se extiende hasta el ápice y presenta sedas erectas dispuestas regularmente en toda su extensión. Segundo protarsómero con prominencia subapical ensanchada, digitiforme (Fig. 58). Segundo mesotarsómero más largo que el tercer tarsómero (Fig. 60). Espolón metatibial superior o interno casi tan largo como el primer metatarsómero, ligeramente recurvado, ancho en su mitad proximal y adelgazado progresivamente hacia el ápice; espolón inferior o externo muy corto, ancho, redondeado de un lado y aguzado del otro (Fig. 61). Segundo metatarsómero claramente más largo que el primero o el tercer tarsómero (Fig. 62). Todas las uñas tarsales con el dentículo inferior más largo y ancho que el dentículo apical (Fig. 59).

Los esternitos $2^{\circ}$ a $4^{\circ}$ excavados en su parte mesial, con algunas sedas cortas esparcidas; el $5^{\circ}$ esternito con la parte media convexa con algunas sedas cortas, y el borde posterior moderadamente elevado. Placa anal corta, convexa, con puntos setíferos irregulares en su mitad distal. Prepigidio poco brillante con numerosos puntos pequeños 
regularmente dispuestos. Placa pigidial uniformemente convexa, brillante, intensamente punteada, sin sedas macroscópicas; el margen apical poco ensanchado y ligeramente levantado, con 12 sedas largas erectas.

Parámeros fusionados basalmente, alargados, un poco deprimidos, recurvados ventralmente, con los extremos apicales parcialmente fusionados, paralelos, estrechos (Figs. 63-65); el saco interno predominantemente membranoso, cubierto con abundantes micro espinas (Fig. 63). Longitud del edeago desde el ápice de los parámeros al extremo de la pieza basal: 4.5-4.7 $\mathrm{mm}$.

Hembra. Similar al macho (Figs. 70-71) excepto: longitud corporal 19.5-20.4 mm, anchura humeral 9.5$11.4 \mathrm{~mm}$. Maza antenal tan larga como los 5 antenómeros precedentes. Espolones metatibiales alargados, ensanchados, moderadamente recurvados, el inferior poco más corto y ancho, ambos con ápices redondeados (Fig. 66). Esternitos convexos finamente punteados, con escasas sedas muy cortas dispersas; placa anal corta, convexa, con puntos irregulares y algunas sedas erectas. Placa pigidial poco convexa, con puntuación irregular poco profunda y algunas sedas microscópicas; márgenes latero apicales estrechos. Placas genitales inferiores esclerosadas, ovaladas, ligeramente asimétricas, poco convexas, con algunas sedas cerca del borde apical; placas genitales superiores pequeñas, con el extremo distal más estrecho y pocas sedas apicales (Fig. 67).

Variación. Longitud corporal 17.0-20.8 mm. Anchura humeral: 9.5-11.4 mm; el color del pronoto y élitros puede variar entre pardo rojizo oscuro y pardo rojizo claro. La cobertura pruinosa dorsal usualmente es poco más intensa en las hembras. La longitud y anchura del espolón metatibial exterior o inferior, así como la curvatura de los parámeros varían ligeramente en muestras de localidades distintas.

Distribución. Alrededores de la cuenca del río Balsas, México (Fig. 109).

Ejemplares examinados. 65 (59 machos, 6 hembras). Paratipo macho etiquetado: "Apatzingán, Michoacan, MEXICO, Alt. 1200 ft August 13 1941" / "W Apatzingán 3 miles" / "Coll. Hoogstraal \& Haag" / "L. W. Saylor Collection" / "PARATYPE hoogstraali L. W. Saylor" (CASC). MEXICO: Guerrero, Iguala, 23-VII-1968, G. Halffter (1) (CNCI); Iguala, Amacuzac, 27-VI-2008, M. Ordoñez y R. Romero (1) (FESZ); Petatlán, Barra de Potosí, VI-2016, M. Romero (2); Zihuatanejo, Playa Blanca, VII-2016, M. Romero (4) (CNIN). Michoacán, Jungapeo, 29-VI-1967, G. Halffter (1) (CNCI); Volcán Jorullo, 8-VII-2004, M. Ordoñez (1) (FESZ). Morelos, 21 mi E Cuernavaca, 1430m, 14-VIII-1954, J. G. Chillcott (1) (CNCI); 5.1 mi E Cuernavaca, 1660 m, 29-VI-1973, R.R. y M.E. Murray (1) (TAMU); Cuernavaca, Palmira, 23VII-1988, L. Arellano (1) (IEXA); Progreso, 4-VII-1948, C. Smith (1) (CNCI); Tepalcingo, El Unicornio, 1327m, 27-V-2011, P. Romero y M Ordoñez (3) (FESZ, MXAL); Tepalcingo, El Limón, 1320m, 17-VI-2010, P. Romero y M Ordoñez (3) (FESZ); Jojutla, Cerro Higuerón, 4-VII-1982,
C. Deloya (1); mismos datos excepto: 9-VI-1985 (1); 26-VI1983 (5); 3-VII-1981 (1); 5-VII-1982 (1); 9-VII-1982 (1); 2-VII-1983 (1); 9-VIII-1983 (4); Acamilpa, Tlaltizapán, 27-VI-1983, C. Deloya (17); Zacatepec, Galeana, 27-VI1983, C. Deloya (3); mismos datos excepto: 28-VI-1983 (2); Tepoztlán, 20-VI-1989, C. Deloya (1); Tepoztlán, 18VI-1989, C. Deloya (9); Yautepec, 1100m, 28-VI-/1989, V. Castrejón (1). Puebla, 9 mi S Izúcar de Matamoros, 8-VI1971, D. H. Bright (1) (CNCI); Chiautla de Tapia, $980 \mathrm{~m}$, 20-V-2006, A. Aragón (1) (MXAL).

Datos biológicos. Habita en ambientes cálidos, subhúmedos, situados entre los 10 y $1700 \mathrm{~m}$ de altitud, originalmente ocupados por bosques tropicales caducifolios, subcaducifolios o matorrales xerófilos. Es una especie poco abundante, los adultos han sido atraídos a las luces eléctricas durante mayo (4), junio (46), julio (8) y agosto (7) y se han observado sobre el follaje de Acacia farnesiana L. (Fabaceae). Se desconocen sus larvas.

Comentarios. Se distingue de otras especies del grupo sobre todo por la estructura crenulada de los bordes laterales del pronoto, la proyección digitiforme subapical del segundo protarsómero en el macho, la forma del espolón metatibial masculino corto, ancho y afilado y las proporciones de los parámeros. También es notable la abundancia de sedas en el borde de las metatibias de los dos sexos.

\section{Phyllophaga (Phytalus) tegulicolis Saylor, 1934}

(Figs. 72-86)

Phyllophaga (Phytalus) tegulicolis Saylor, 1934. Pomona College J. Entomology and Zoology 26: 49

Phyllophaga tegulicollis Saylor. Blackwelder (1944: 226) Phyllophaga (Phytalus) tegulicollis Saylor. Morón (1994: 63)

Phyllophaga tegulicolis Saylor. Evans (2003: 161)

Redescripción: Machos. Longitud total del cuerpo: 16.2-17.5 mm. Anchura humeral: 7.4-7.6 mm. Relación longitud /anchura cuerpo: 2.3:1.0. Cabeza de color pardo oscuro negruzco brillante; pronoto pardo oscuro a pardo rojizo ligeramente pruinoso; élitros pardo rojizo con cubierta pruinosa blanquecina; patas de color pardo oscuro a rojizo brillante; abdomen pardo amarillento, opaco, con cubierta pruinosa ligera blanquecina (Figs. 72-73). Clípeo 2.3 veces más ancho que largo, redondeado, con el borde anterior ligeramente sinuado y los márgenes levantados; el disco clipeal ligeramente cóncavo a los lados, con abundante puntuación circular, somera, y escasas sedas diminutas. Sutura fronto-clipeal bien definida, poco sinuada (Fig. 76). Frente convexa 2.2 veces más ancha que larga, con puntuación circular amplia en la mitad anterior y estrecha en la parte posterior, y numerosas sedas delgadas erectas. Tercer antenómero semicilíndrico, poco más largo que el $4^{\circ}$ o el $5^{\circ}$ que muestran ligeras prominencias anteriores redondeadas; antenómeros $6^{\circ}$ y $7^{\circ}$ más anchos que largos, cada uno con una proyección anterior redondeada 
corta. Maza antenal poco más larga (1.2:1.0) que los seis antenómeros precedentes. La anchura dorsal de cada ojo es equivalente al $48 \%$ de la distancia interocular. Canthus ocular con 8-10 sedas erectas.

Pronoto 2.3 veces más ancho que largo; la relación anchura máxima de la cabeza-anchura máxima del pronoto es de 0.62:1.00 y la relación distancia interocular-anchura máxima del pronoto es de $0.46: 1.00$; superficie del disco pronotal uniformemente convexa, con vestidura pruinosa microscópica ligera, con puntos redondos pequeños, bien definidos, someros, escasos hacia el centro del disco, con sedas de diferente longitud irregularmente dispuestas; márgenes laterales ligeramente crenulados sobre todo en la mitad posterior; ángulos anteriores obtusos, prominentes; ángulos posteriores obtusos, prominentes (Fig. 76). Escutelo más ancho que largo (1.5:1.0) casi liso, pruinoso, con 4-6 puntos pequeños dispersos hacia cada lado. Élitros 2.6 veces más largos que anchos, con superficie ligeramente rugosa y abundantes puntos circulares, irregulares, con sedas cortas, distribuidos uniformemente; reborde de la epipleura estrecho, se extiende hasta el ápice y presenta sedas erectas dispersas sobre todo en la mitad posterior. Segundo protarsómero con prominencia subapical corta y estrecha. Segundo mesotarsómero más largo que el tercer tarsómero. Espolón metatibial superior o interno más corto que el primer metatarsómero, ligeramente recurvado, con ápice redondeado; espolón inferior o externo muy largo, delgado, recurvado con ápice redondeado (Fig. 77). Segundo metatarsómero claramente más largo que el primero o el tercer tarsómero. Todas las uñas tarsales con el dentículo inferior poco más largo y ancho que el dentículo apical (Fig. 78).

Los esternitos $2^{\circ}$ a $4^{\circ}$ ligeramente deprimidos en su parte mesial, con sedas cortas esparcidas; el $5^{\circ}$ esternito con la parte media convexa, con sedas cortas, y el borde posterior apenas elevado. Placa anal corta, poco convexa, con puntos setíferos irregulares. Prepigidio opaco con numerosos puntos setíferos pequeños regularmente distribuidos. Placa pigidial uniformemente convexa, pruinosa, con abundantes puntos someros y sedas cortas; el margen apical poco ensanchado y ligeramente levantado, con 6-8 sedas erectas.

Parámeros fusionados basalmente, alargados, redondeados, un poco recurvados ventralmente, con los extremos apicales cercanamente fusionados, redondeados (Figs. 79-81); el saco interno predominantemente membranoso, con dos laminillas esclerosadas dorsales $\mathrm{y}$ una proyección espiniforme preapical, rodeadas por abundantes micro espinas (Fig. 84). Longitud del edeago desde el ápice de los parámeros al extremo de la pieza basal: $5.4-5.6 \mathrm{~mm}$.

Hembra. Similar al macho (Figs. 74-75) excepto: longitud corporal 17.0-18.3 mm. Anchura humeral: 7.5$7.7 \mathrm{~mm}$. Maza antenal tan larga como los 5-6 antenómeros precedentes. Espolones metatibiales alargados, recurvados, el superior poco más corto, ambos con ápices redondeados
(Fig. 82). Esternitos convexos finamente punteados, con escasas sedas cortas dispersas; placa anal corta, muy convexa, con puntos irregulares y algunas sedas erectas. Placa pigidial convexa, con abundantes sedas cortas erectas y puntuación irregular poco profunda en el disco y una ligera depresión semirrugosa preapical; margen apical poco engrosado. Placas genitales inferiores esclerosadas, alargadas, ovaladas, ligeramente asimétricas, poco convexas, con algunas sedas cortas cerca del borde apical; placas genitales superiores más pequeñas, con el extremo distal casi truncado con pocas sedas apicales (Fig. 83).

Variación. Longitud corporal 16.2-18.3 mm. Anchura humeral: 7.4-7.7 mm.; el color del pronoto y élitros abarca entre pardo rojizo oscuro y pardo rojizo claro. La vestidura setífera y la pruinosidad dorsal varían ligeramente, y son poco más abundantes en las hembras. El ápice de los parámeros es delgado (Fig. 84) en el holotipo. Los parámeros y la pieza basal son más robustos en ejemplares de Morazán, Honduras (Figs. 85-86).

Distribución. Depresión central de Chiapas, México al sur de Honduras (Fig. 109).

Ejemplares examinados. 18 (11 machos, 7 hembras). Holotipo macho etiquetado: "Honduras, Tegucigalpa, May 10, 1911, F. I. Dyer" / "holotype 54367" / "Phyllophaga tegulicollis Saylor" (NMNH). GUATEMALA: Santa Rosa, Taxisco, 220 m, 15-V-1998, G. Chinchilla (4) (UVGC, MXAL). HONDURAS: $30 \mathrm{~km}$ E Tegucigalpa, 25-IV-1979, J. Inashima (1) (FSCA); Morazán, Esc. Agr. Panamericana El Zamorano, 15-IV-1988, R. Cave (2) (TAMU, MXAL); 7 km N Guinope, 1200 m, 8-VI-1994, B. D. Gill (5) (BDGC). MEXICO: Chiapas, Chiapa de Corzo, 9-VIII-1969, D. Kritsch (1) (CNCI); 7.2 mi SE Chiapa de Corzo, 8-VII1971, Clark, Murray, Hart, Schaffner (4) (TAMU, MXAL).

Datos biológicos. Habita en ambientes cálidos, subhúmedos, situados entre los 200 y $1200 \mathrm{~m}$ de altitud, originalmente ocupados por bosques tropicales caducifolios, subcaducifolios o matorrales xerófilos. Es una especie poco abundante, los adultos han sido atraídos a las luces eléctricas durante abril (3), mayo (5), junio (5), julio (4) y agosto (1). Se desconocen sus hábitos y larvas.

Comentarios. Se distingue por la vestidura setífera esparcida en el pronoto y élitros, la forma del espolón metatibial masculino inferior alargado, estrecho y afilado y las proporciones de los parámeros y la pieza basal. Es muy parecida a $P$. tegenara, aunque tiene un tamaño corporal poco más grande y robusto. El nombre específico en la publicación original se imprimió como "tegulicolis" posiblemente por error, ya que debería ser "tegulicollis" para tener una etimología latinizada correcta: tegulum, cubierta o revestimiento; collis, elevación, parte dorsal = "dorso revestido"; pero atendiendo a las recomendaciones del CINZ no debe cambiarse la grafía original a menos que exista una confusión con nombres similares.

\section{Phyllophaga (Phytalus) tegenara Saylor, 1935}

(Figs. 87-107) 
Phyllophaga (Phytalus) tegenara Saylor, 1935. Revista de Entomología 5: 496

Phyllophaga tegenara Saylor. Blackwelder (1944: 226)

Phyllophaga (Phytalus) tegenara Saylor. Morón (1994: 63)

Phyllophaga (Phytalus) tegenara Saylor. Solís y Morón (1998: 22)

Phyllophaga tegenara Saylor. Evans (2003: 161)

Redescripción: Machos. Longitud total del cuerpo: 14.6-15.4 mm. Anchura humeral: 6.6-6.8 mm. Relación longitud /anchura cuerpo: 2.2:1.0. Cabeza de color pardo rojizo oscuro brillante; pronoto pardo rojizo ligeramente pruinoso; élitros pardo rojizo con cubierta pruinosa blanquecina densa; patas de color pardo rojizo brillante; abdomen pardo amarillento, opaco, con cubierta pruinosa ligera blanquecina (Figs. 87-88, 91-92). Clípeo 2.3 veces más ancho que largo, redondeado, con el borde anterior ligeramente sinuado y los márgenes levantados; el disco clipeal ligeramente cóncavo a los lados, con puntuación circular, somera, dispersa y escasas sedas diminutas. Sutura fronto-clipeal bien definida, escotada (Fig. 95). Frente convexa 2.3 veces más ancha que larga, con puntuación irregular en los dos tercios anteriores, dispersa en el tercio posterior, y numerosas sedas delgadas erectas. Tercer antenómero semicilíndrico, tan largo como el $4^{\circ}$ o el $5^{\circ}$ que muestran ligeras prominencias anteriores redondeadas; antenómeros $6^{\circ}$ y $7^{\circ}$ más anchos que largos, el $7^{\circ}$ con una proyección laminar corta. Maza antenal poco más larga (1.2:1.0) que los seis antenómeros precedentes. La anchura dorsal de cada ojo es equivalente al $48 \%$ de la distancia interocular. Canthus ocular con 10-12 sedas erectas.

Pronoto 2.4 veces más ancho que largo; la relación anchura máxima de la cabeza-anchura máxima del pronoto es de 0.64:1.00 y la relación distancia interocular-anchura máxima del pronoto es de 0.48:1.00; superficie del disco pronotal uniformemente convexa, con vestidura pruinosa microscópica ligera, con puntos redondos pequeños, bien definidos, someros, más abundantes hacia los bordes, con sedas de diferente longitud irregularmente dispuestas; márgenes laterales ligeramente crenulados en toda su extensión; ángulos anteriores obtusos, prominentes; ángulos posteriores obtusos, poco prominentes (Fig. 95). Escutelo más ancho que largo (1.5:1.0) casi liso, pruinoso, con 2-3 puntos setíferos pequeños dispersos hacia cada lado. Élitros 2.6 veces más largos que anchos, con superficie ligeramente rugosa y abundantes puntos circulares, regulares, con sedas cortas, esparcidos uniformemente; reborde de la epipleura estrecho, se extiende hasta el ápice y presenta sedas erectas dispersas en toda su extensión. Segundo protarsómero con prominencia subapical corta y estrecha (Fig. 96). Segundo mesotarsómero poco más largo que el tercer tarsómero. Espolón metatibial superior o interno más corto que el primer metatarsómero, casi recto con ápice redondeado; espolón inferior o externo muy largo, delgado, poco recurvado antes del ápice redondeado (Fig. 98). Segundo metatarsómero claramente más largo que el primero o el tercer tarsómero. Todas las uñas tarsales con el dentículo inferior poco más largo y ancho que el dentículo apical (Fig. 97).

Los esternitos $2^{\circ}$ a $4^{\circ}$ ligeramente convexos en su parte mesial, con sedas cortas esparcidas; el $5^{\circ}$ esternito con la parte media convexa, con sedas cortas, y el borde posterior casi plano. Placa anal corta, con reborde basal redondeado y puntos setíferos irregularmente distribuidos. Prepigidio opaco con numerosos puntos setíferos pequeños regularmente distribuidos. Placa pigidial poco convexa, ligeramente pruinosa, con puntos someros irregulares y sedas cortas dispersas; el margen apical poco ensanchado, redondeado y ligeramente levantado, con 8-10 sedas apicales erectas.

Parámeros fusionados basalmente, alargados, redondeados, un poco recurvados ventralmente, con los extremos apicales cercanamente fusionados, redondeados (Figs. 99-101); el saco interno predominantemente membranoso, con dos laminillas esclerosadas dorsales y una proyección digitiforme preapical, rodeadas por abundantes micro espinas (Fig. 101). Longitud del edeago desde el ápice de los parámeros al extremo de la pieza basal: $5.1-5.3 \mathrm{~mm}$.

Hembra. Similar al macho (Figs. 89-90, 93-94) excepto: longitud corporal 15.4-15.8 mm. Anchura humeral: 6.8-7.0 $\mathrm{mm}$. Maza antenal casi tan larga como los cinco antenómeros precedentes. Espolones metatibiales alargados, poco recurvados, el superior poco más estrecho, ambos con ápices redondeados (Fig. 102). Esternitos convexos finamente punteados, con escasas sedas cortas dispersas; placa anal corta, convexa, con puntos irregulares y algunas sedas erectas. Placa pigidial convexa, poco pruinosa, con numerosas sedas cortas erectas y puntuación irregular poco profunda; margen apical poco engrosado. Placas genitales inferiores esclerosadas, alargadas, ovaladas, casi simétricas, poco convexas, con algunas sedas cortas cerca del borde apical; placas genitales superiores más pequeñas, redondeadas, con pocas sedas apicales (Fig. 103).

Variación. Longitud corporal 14.6-15.8 mm. Anchura humeral: 6.6-7.0 $\mathrm{mm}$; el color del pronoto y élitros abarca entre pardo rojizo oscuro y pardo rojizo claro. La vestidura setífera y la pruinosidad varía ligeramente en los élitros, y es poco más abundante en las hembras. En los machos de Nicaragua el espolón metatibial inarticulado es muy recto (Fig. 104). Los parámeros son más alargados y estrechos en los ejemplares de Costa Rica (Fig. 101), y la pieza basal es más corta en los machos de Granada (Fig. 105-106) Los parámeros del holotipo son menos largos (Fig. 107) y el espolón metatibial inferior está ligeramente recurvado.

Distribución. Suroeste de Nicaragua y oeste de Costa Rica (Fig. 109).

Ejemplares examinados. 295 (147 machos, 148 hembras). Holotipo macho etiquetado: "Guanacaste CR May 1932, P. Assmann leg." / "holotype 54560" / "Phyllophaga tegenara Saylor" (NMNH). COSTA RICA: Guanacaste, Parque Nacional Guanacaste, Agua Buena, 
220m, 1-VI-1992 (1) (MXAL); La Pacifica, nr Cañas, 8-VI-1983, J. Wappes (3) (FSCA); Parque Nacional Santa Rosa, Estación Santa Rosa, 300m, 3-VI-1992 (1) (MXAL); El Ocotal, 17-V-1989, R. H. McPeak (1) (MXAL); P. N. Barra Honda, A. C. Tempisque, 100 m, V-1994, M. Reyes (2); mismos datos excepto: VI-1994 (2); 3 km NO de Nacaome, 100 m, IV-1993, M. Reyes (8); V-1988, W. Hallwachs, D. H. Janzen (4); 5-VII-1992, M. Reyes (1); 30-V-1993 (4); VII-1995 (1); 16-V-1988, D. Janzen (17); 3-VII-1993, M. Reyes (2); IV-1995 (1); Cañas, Bebedero, Fca. Las Vegas. 100 m, 28-IV-2011, A. Solís (1); Refugio Nac. Fauna Silv. R. L. Rodríguez, Estación Palo Verde, 10 m, VI-1991, U. Chavarría (2); Est. Lomas Barbudal, 30 m, VII-1991, D. Acevedo (1); Tierras Morenas, Tilaran, A. C. Arenal, 685 m, V-1994, G. Rodríguez (1); Estación Experimental Horizontes, A. C. 100-150 m, VI-1993, P. Ríos (4); Rincochita Lodge S Rincón de la Vieja, 608m. 21-V-2003, Cate, Barries, Uhler (1); Liberia, Parque Nal. Santa Rosa, Estación Santa Rosa, 300m, 15-V-1978, Janzen (2); mismos datos excepto: VI-1991, D. H. Janzen \& W. Hallwachs (3); 12-VI-1992, A. Mora (7); 3-VI-1992 (29); II-1992, F. Araya (2); VII-1992, D. H. Janzen, W. Hallwachs (1); 25-VII-1986, A. Solís (1); 14-V-1978, D. H. Janzen (12); 17-V-1979 (1); 8-VI-1978 (7); 22-V-1980 (1); 28-VI-1977 (1); 17-VI-1977 (1); 12-III-1978 (5); 14VI-1977 (12); La Cruz, Parque Nal Santa Rosa, 280-300m. 14-V-1978, Janzen (3); Fca. Jenny, $30 \mathrm{~km} \mathrm{~N}$ de Liberia, P. N. Guanacaste, 20-III-1993, E. Araya (13); mismos datos excepto: 25-IV-1993 (2); 30-V-1994 (1); 14-V-1996 (2); 240 m, 29-VI-1996 (15); 16-VII-1993 (1); 21-VIII1993 (3); Estación Murciélago, 80m, 19-IX-1994, F. A. Quesada (1); Est. Murciélago, $8 \mathrm{~km}$ SO. de Cuajinicuil, P. N. Guanacaste, 100 m, 23-VI-1994, C. Cano (1); mismos datos excepto: 13-VI-1992 (19); Bahía Santa Elena, P. N. Guanacaste, A. C. 100 m, 11-VI-1994, F.A. Quesada (1); Casa Oeste, Cerro El Hacha, $12 \mathrm{~km}$ SE La Cruz, 300m, IX-1987 (10); Cerro El Hacha, 300 m, 12 km SE La Cruz, V-1988, M. Espinoza (6); La Cruz, Lado SSW Cerro El Hacha, 26-VII-1986, I. A. Chacón (1); SSW side Cerro El Hacha 300-400m, 31-V-1986, DH Janzen \& W. Hallwachs (4); Agua Buena, 220m, P. N. Guanacaste, VI-1992 (13); Est. Los Almendros, P. N. Guanacaste, A. C. 300 m, 8-VI1994, E. E. López (1); mismos datos excepto: 12-V-1993 (2); $12 \mathrm{Km}$ Carretera, Sta Cecilia, 300m, 17-V-1996 (3); 22-IV-1995 (8); 8-V-1994 (1); La Cruz, nr. Río Sapoa, 130 m, 13-V-2006, Holzer \& Erwin (1). Puntarenas, R.N Cabo Blanco Est. San Miguel, IX-1993, M. Ramírez (1); Esparza. San Luis, Ortuño, Lote Variedades, 200-300m, 17V-2011, A. Solís (1). NICARAGUA: Carazo, San Marcos, 700m, 3-V-1999, E. van der Berghe (2) (MELN, MXAL). Chinandega: Mina El Limón, D. Cruz (3) (MELN). Granada, R. S. P. Domitila, 55m, 25-V-2003, J.M. Maes (19) (MELN, MXAL); mismos datos excepto 1-VI-2002 (9) MELN). Jinotega, Santa Enriqueta, 1250 m, 30-V2003, D. Roiz (1). Masaya, Las Flores, 10-VI-1999, F. Téllez (1 MELN); Las Flores, V-2000, M. Téllez (1). Rivas,
Tola, Talón de Brito, 6-VII-2008, J.M. Maes (3) (MELN).

Datos biológicos. Habita en ambientes cálidos, subhúmedos, situados entre el nivel del mar y los 1250 $\mathrm{m}$ de altitud, situados hacia la vertiente del Pacífico en Nicaragua y Costa Rica, originalmente ocupados por bosques tropicales caducifolios. Es una especie abundante, los adultos han sido atraídos a las luces eléctricas durante febrero (3), marzo (18), abril (21), mayo (94), junio (132), julio (12), agosto (3) y septiembre (12), y en Guanacaste Daniel Janzen (in lit.) los colectó sobre follaje de Gouania poligama (Jacq.) Urb. (Rhamnaceae), Ayenia micrantha Stanley (Malvaceae) y Cordia alliodora Ruiz et Pav. (Boraginaceae), y en botones florales de Zanthoxylum setulosum Wilson (Rutaceae). Se desconocen sus larvas.

Comentarios. Es muy parecida a P. tegulicolis, aunque tiene un tamaño corporal más pequeño y esbelto. Se distingue por la puntuación menos intensa en la cabeza, el pronoto y élitros, la forma del espolón metatibial masculino inferior más alargado y estrecho, las proporciones de los parámeros y la pieza basal, y la forma de los escleritos dorsales preapicales del saco interno.

\section{AGRADECIMIENTOS}

Alas siguientespersonaseinstitucionespor las facilidades otorgadas para consultar las colecciones a su cargo: L. H. Herman, Jr. (AMNH), D. H. Kavanaugh (CASC), F. Genier $(\mathrm{CMNC})$, S. Leplante y B. D. Gill (CNCI), S. Zaragoza (CNIN), L. E. Rivera (CUCsur), M. Ordóñez (FESZ), R. E. Woodruff (FSCA), R. Snelling (LACM), J. M. Maes (MELN), A. Solís (MNCR), N. Vandenberg (NMNH), E. G. Riley (TAMU) y E. Cano (UVGC). Antoine Mantilleri (MNHN) envió valiosas fotografías del tipo de $P$. pruinosa. Sara L. Rivera (INECOL) aportó información útil para el análisis comparativo de los caracteres morfológicos que distinguen al grupo "pruinosa". Miguel Romero (UAM-X) proporcionó datos relevantes y preparó la ilustración de la figura 66. Roberto Arce y César V. Rojas (INECOL) colaboraron en aspectos técnicos. Agustín Aragón (BUAP) y Guillermo Nogueira (Guadalajara) donaron ejemplares valiosos para completar este trabajo, que representa una contribución a la línea de investigación sobre "Sistemática, biología e importancia de los Coleópteros Lamelicornios de América Latina", apoyada por el INECOL (cuenta 2003010011).

\section{LITERATURA CITADA}

Blackwelder, R. E. 1944. Checklist of the coleopterous insects of Mexico, Central America, the West Indies, and South America. Part 2. Bulletin United States National Museum 185: 189-341.

Böving, A. G. 1942. A classification of larvae and adults of the genus Phyllophaga (Coleoptera: Scarabaeidae). Memoirs of the Entomological Society of Washington 2: $1-96$

Dalla-Torre, K. W. 1912. Scarabaeidae: Melolonthinae III Pars 49. Vol. 20. (pp. 135-290). In: S. Schenkling (ed.). 
Coleopterorum Catalogus. W. Junk, Berlin.

Evans, A. V. 2003. A checklist of the New World chafers (Coleoptera: Scarabaeidae, Melolonthinae). Zootaxa (211): 1-458.

Frey, G. 1975. Bestimmungstabelle der südamerikanischen Arten der Gattung Phyllophaga Harris und ihrer Untergattung Phytalus Er. (Col. Melolonthidae). Entomologische Arbeiten Museum G. Frey 26: 201-226.

Morón, M. A. 1986. El género Phyllophaga en México. Morfología, distribución y sistemática supraespecifica. Instituto de Ecología, México.

Morón, M. A. 1996. Coleópteros Melolonthidae asociados con las flores de Hibiscus rosa-sinensis L. (Malvaceae) en la región de Xalapa, Veracruz, México. Giornale italiano di Entomología 8(2): 111-123.

Morón, M. A. 2003. Revision of the Phyllophaga s.s. schizorhina species group (Coleoptera: Melolonthidae; Melolonthinae). The Canadian Entomologist 135 (2): 213-302.

Morón, M. A. 2006. Revisión de las especies de Phyllophaga (Phytalus) grupos obsoleta y pallida (Coleoptera: Melolonthidae: Melolonthinae). Folia Entomológica Mexicana 45_(Supl.1): 1-104.

Morón, M. A. 2013. Revisión del nuevo grupo de especies orosina de Phyllophaga (s. str.) (Coleoptera: Melolonthidae). Elytron 26: 49-76.

Morón, M. A. 2017. Sinopsis del nuevo grupo de especies "puberea" de Phyllophaga (Phytalus) (Coleoptera: Melolonthidae: Melolonthinae). Elytron 29: 3-33.
Rivera-Gasperín, S. L. y M. A. Morón. 2013. Análisis filogenético del subgénero Phyllophaga (Triodonyx) (Coleoptera: Melolonthidae: Melolonthinae). Revista Mexicana Biodiversidad 84: 802-817.

Rivera-Gasperín, S. L. y M. A. Morón. 2017a. Phylogenetic relationships within Phyllophaga Harris (sensu lato) (Coleoptera: Melolonthidae, Melolonthinae) with emphasis on Listrochelus Blanchard. Neotropical Entomology 46(5):524-536.

Rivera-Gasperín, S. L. y M. A. Morón. 2017b. Relaciones filogenéticas de las especies de Chlaenobia con otros miembros de Phyllophaga (s. lato) (Coleoptera: Melolonthidae: Melolonthinae). Revista Mexicana de Biodiversidad 88(3): 592-607.

Sanderson, M. L. 1958. Faunal affinities of Arizona Phyllophaga, with notes and descriptions of new species. Journal of the Kansas Entomological Society 31(2): 158-173.

Saylor, L. W. 1942. Notes on beetles related to Phyllophaga Harris with descriptions of new genera and subgenera. Proceedings United States National Museum 92 (3145): 157-165.

Simeón, R. 1977. Diccionario de la lengua Náhuatl o Mexicana. Siglo XXI Editores, México.

Wheeler, Q. D. and N. I. Platnick. 2000. The phylogenetic species concept (sensu Wheeler and Platnik). (pp. 5569) In: Wheeler, Q. D. and R. Meier (eds.). Species concepts and phylogenetic theory: a debate. Columbia University Press, New York.

Recibido: 13 de julio 2017

Aceptado: 21 de agosto 2017 

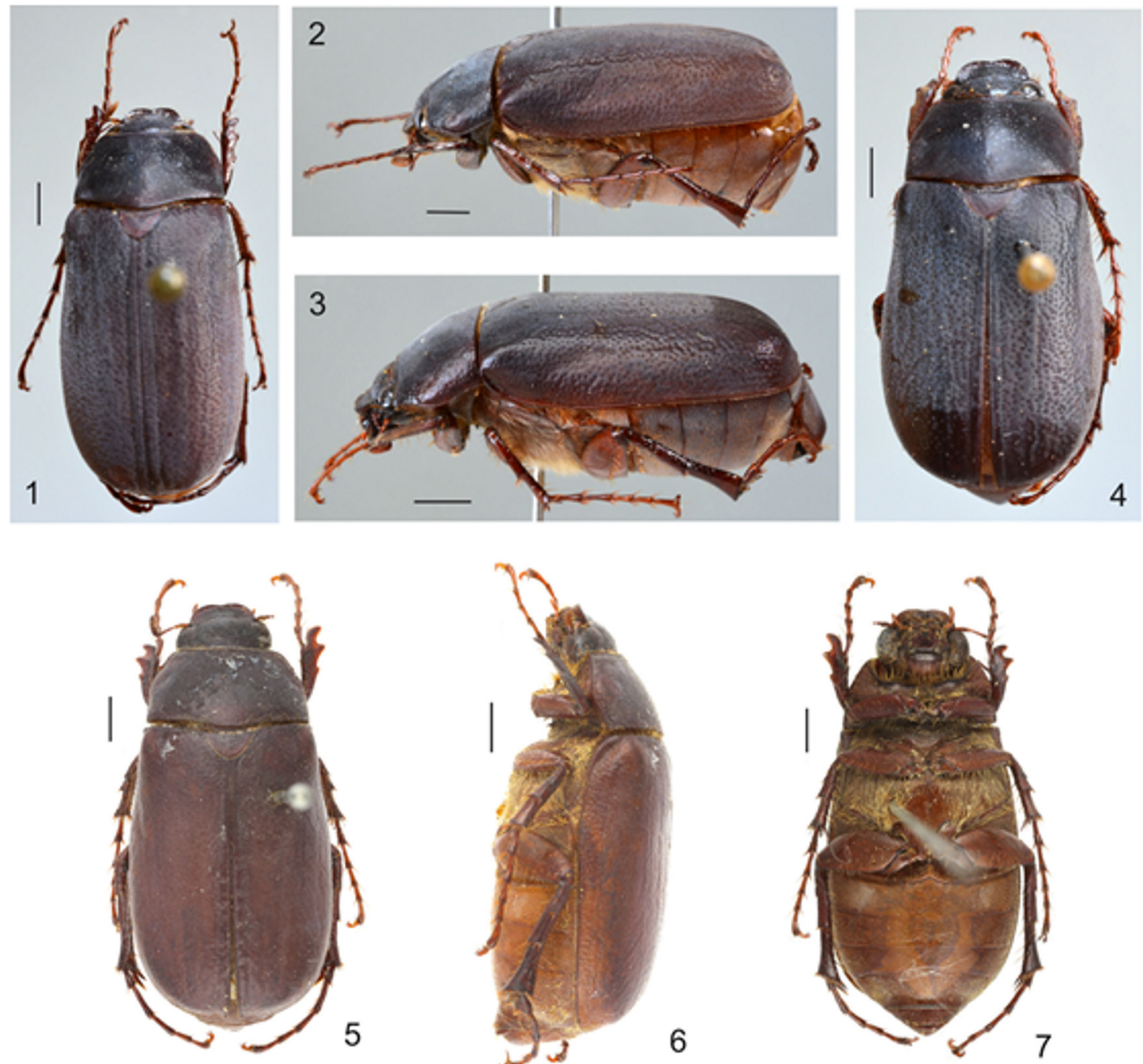

4

5
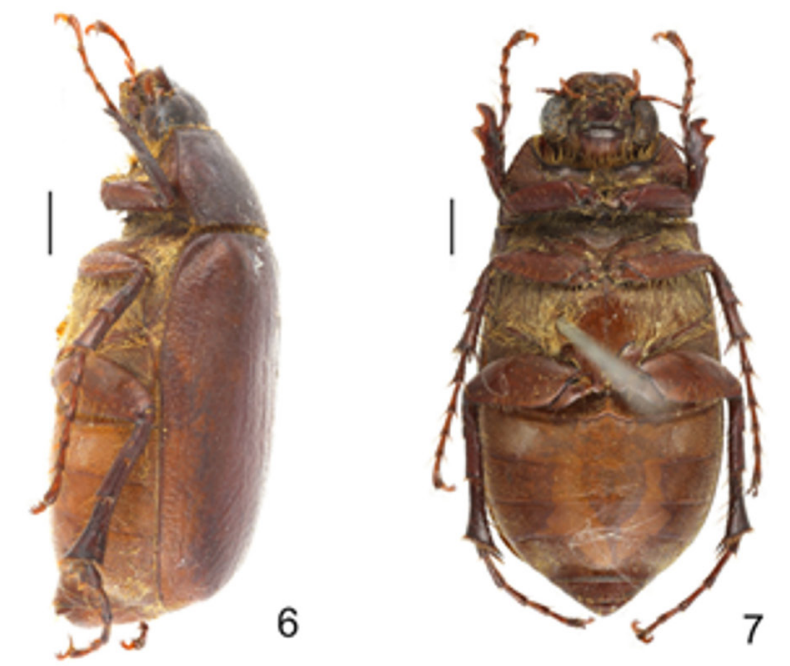

Figuras 1-7. Phyllophaga pruinosa, macho de Coatepec, Veracruz: 1) Aspecto dorsal. 2) Lateral. Hembra de Xalapa, Veracruz: 3) Lateral. 4) Dorsal. Lectotipo hembra: 5) Dorsal. 6) Lateral. 7) Ventral. Líneas de escala = $2 \mathrm{~mm}$. 

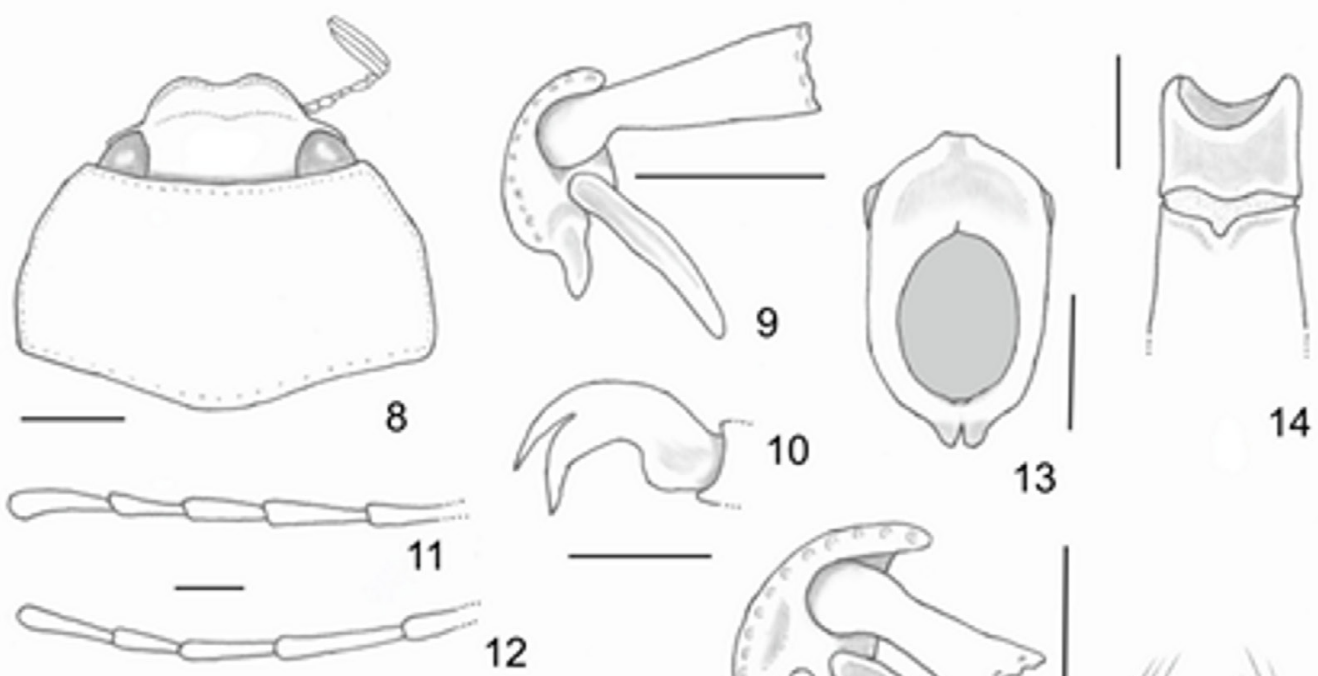

13

14

12
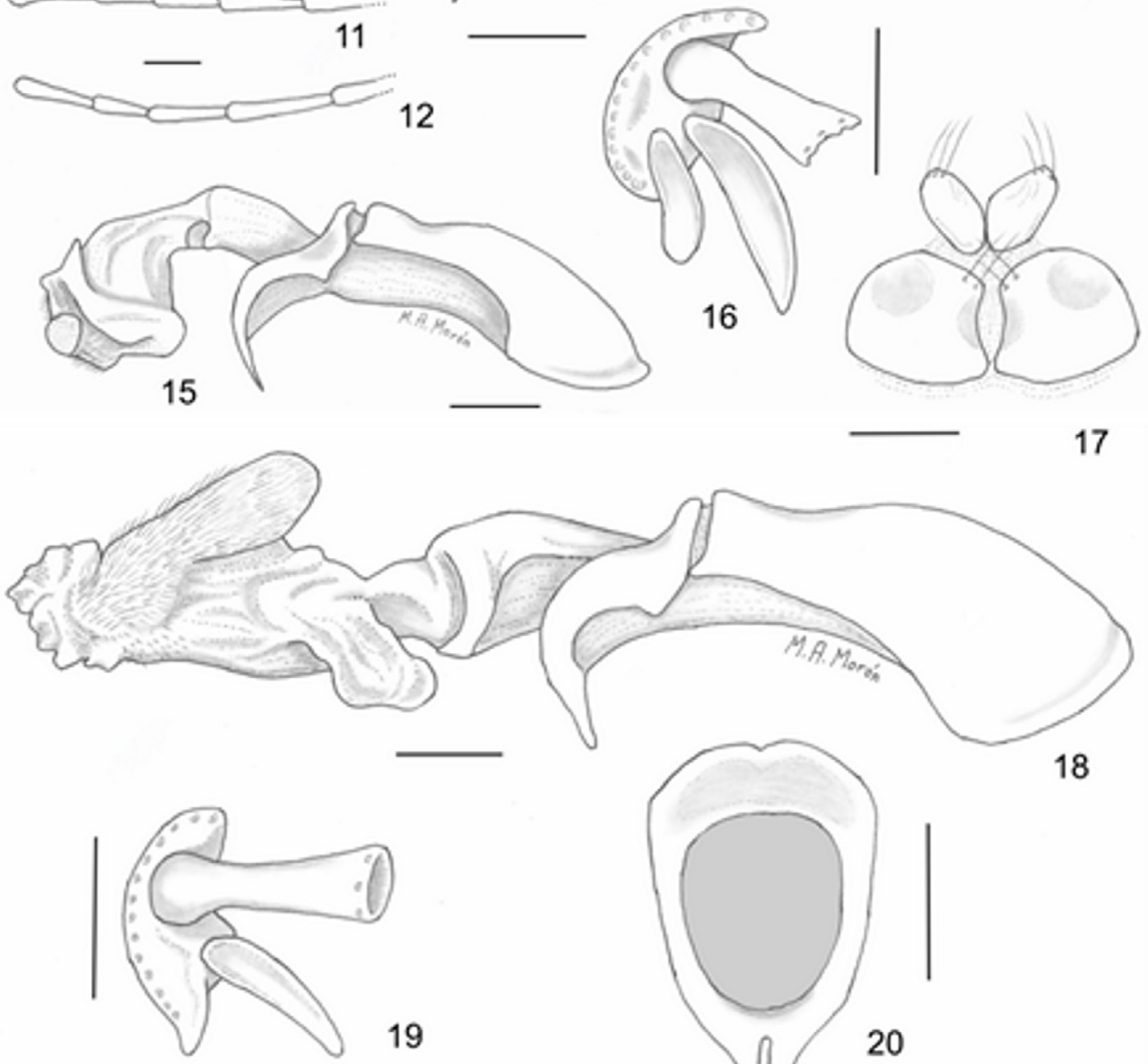

19

17

Figuras 8-20. Phyllophaga pruinosa, macho de Comaltepec, Oaxaca: 8) Cabeza y pronoto. 9) Ápice de la metatibia, distal. 10) Uña protarsal externa. 11) Mesotarsómeros. 12) Metatarsómeros. 13) Parámeros, distal. 14) Falobase. 15) Cápsula genital completa, lateral. Hembra de Coatepec, Veracruz: 16) Ápice de la metatibia, distal. 17) Placas genitales, ventral. Macho de Pejibaye, Cartago, Costa Rica: 18) Cápsula genital completa, lateral. 19) Ápice de la metatibia, distal. 20) Parámeros, distal. Líneas de escala $=1 \mathrm{~mm}$, excepto fig. $8=2 \mathrm{~mm}$, fig. $10=0.5 \mathrm{~mm}$. 

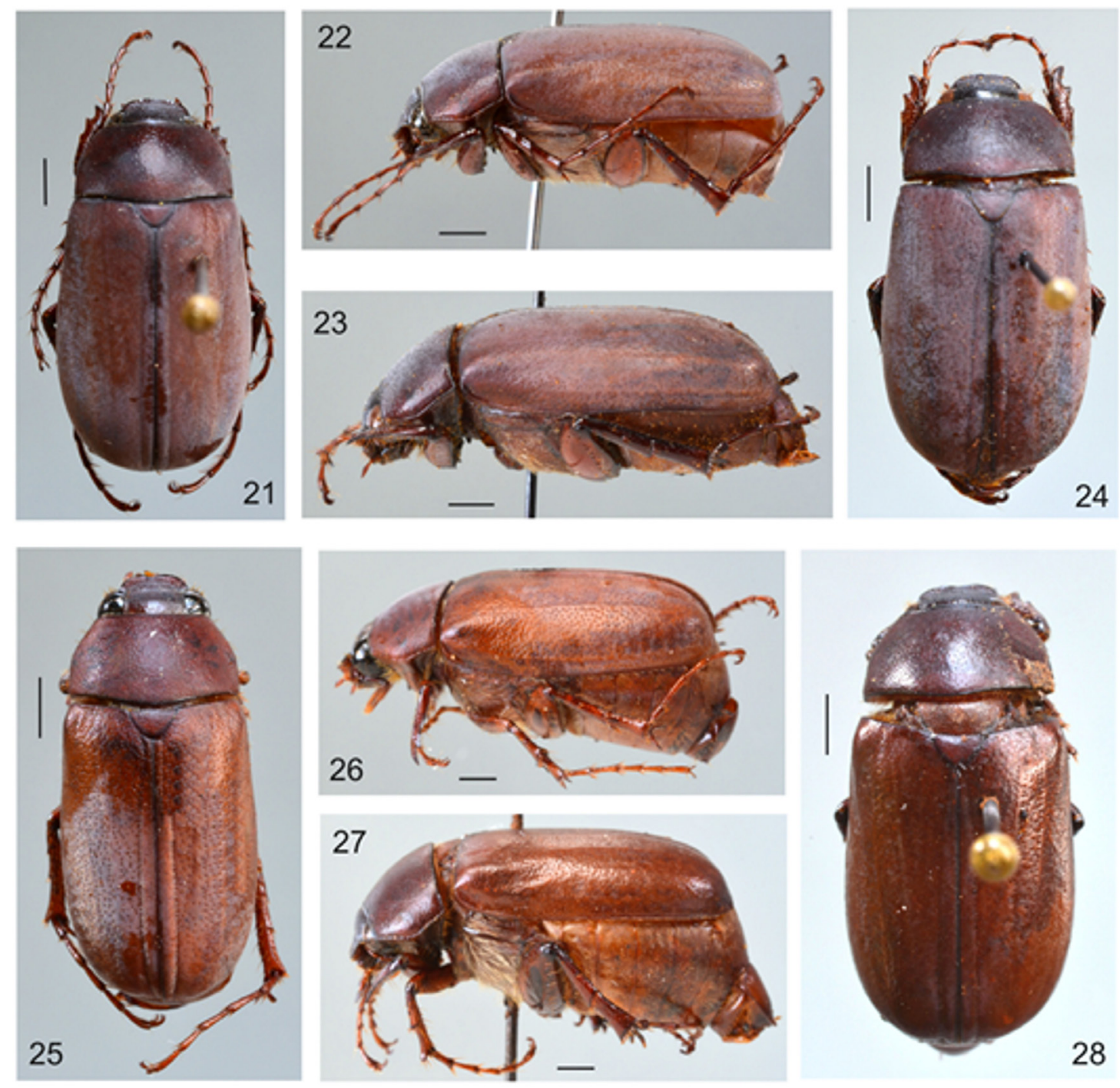

Figuras 21-28. Phyllophaga tlilloa, macho de Tepic, Nayarit: 21) Vista dorsal. 22) Lateral. Hembra de Tepic: 23) Lateral. 24) Dorsal. Figuras 25-28. Phyllophaga yautepecana, macho de El Camarón, Yautepec, Oaxaca: 25) Dorsal. 26) Lateral. Hembra de Yautepec: 27) Lateral. 28) Dorsal. Líneas de escala $=2 \mathrm{~mm}$. 

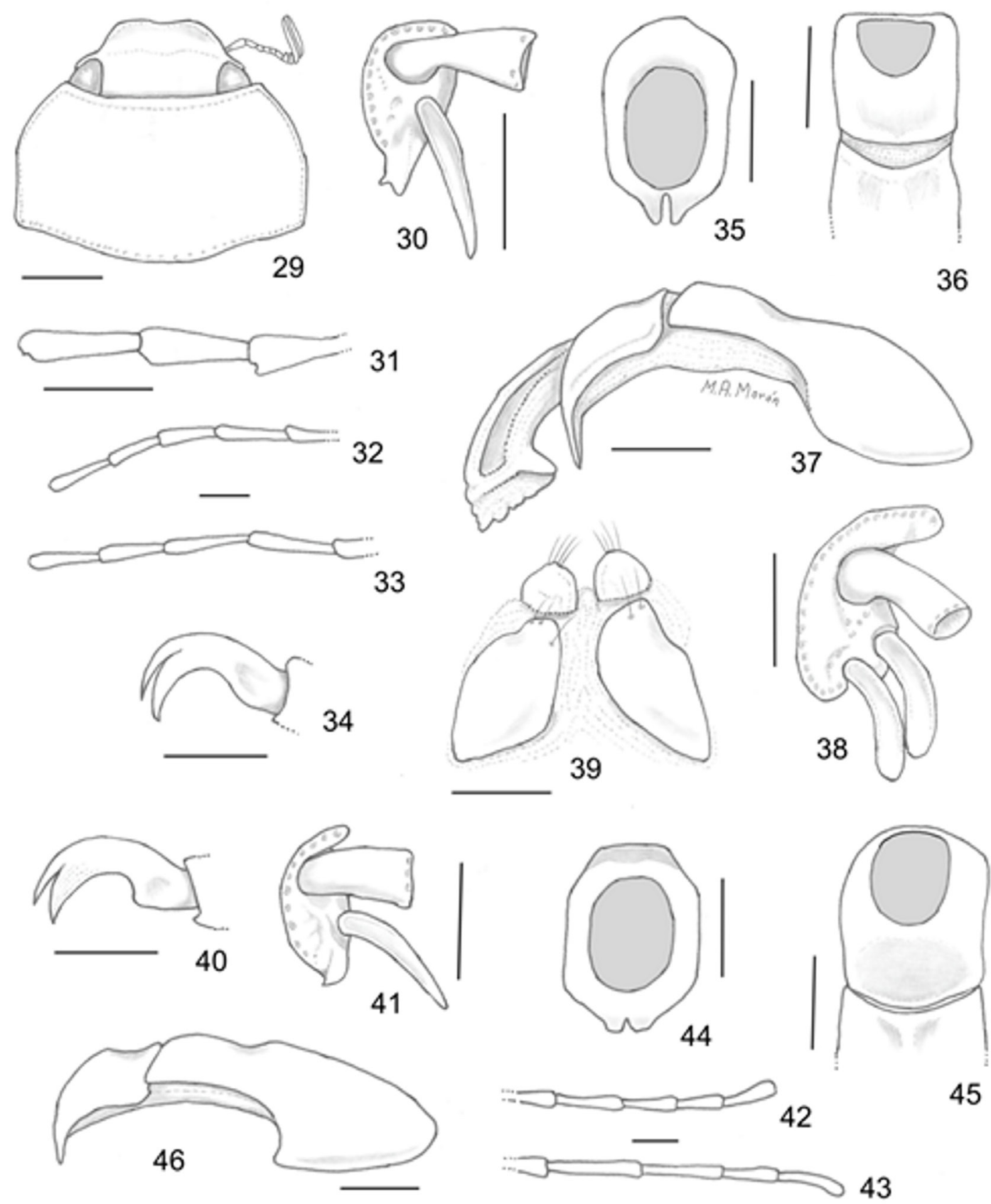

Figuras 29-46. Phyllophaga tlilloa, macho de Tepic, Nayarit: 29) Cabeza y pronoto. 30) Ápice de la metatibia, distal. 31) Segundo a cuarto protarsómeros. 32) Mesotarsómeros. 33) Metatarsómeros. 34) Uña protarsal externa. 35) Parámeros, distal. 36) Falobase. 37) Cápsula genital completa, lateral. Hembra de Tepic: 38) Ápice de la metatibia, distal. 39) Placas genitales, ventral. Macho de Chiautla, Puebla: 40) Uña protarsal externa. 41) Ápice de la metatibia, distal. 42) Mesotarsómeros. 43) Metatarsómeros. 44) Parámeros, distal. 45) Falobase. 46) Parámeros y pieza basal, lateral. Líneas de escala $=1 \mathrm{~mm}$, excepto fig. $29=2 \mathrm{~mm}$, figs. $34,40=0.5 \mathrm{~mm}$. 

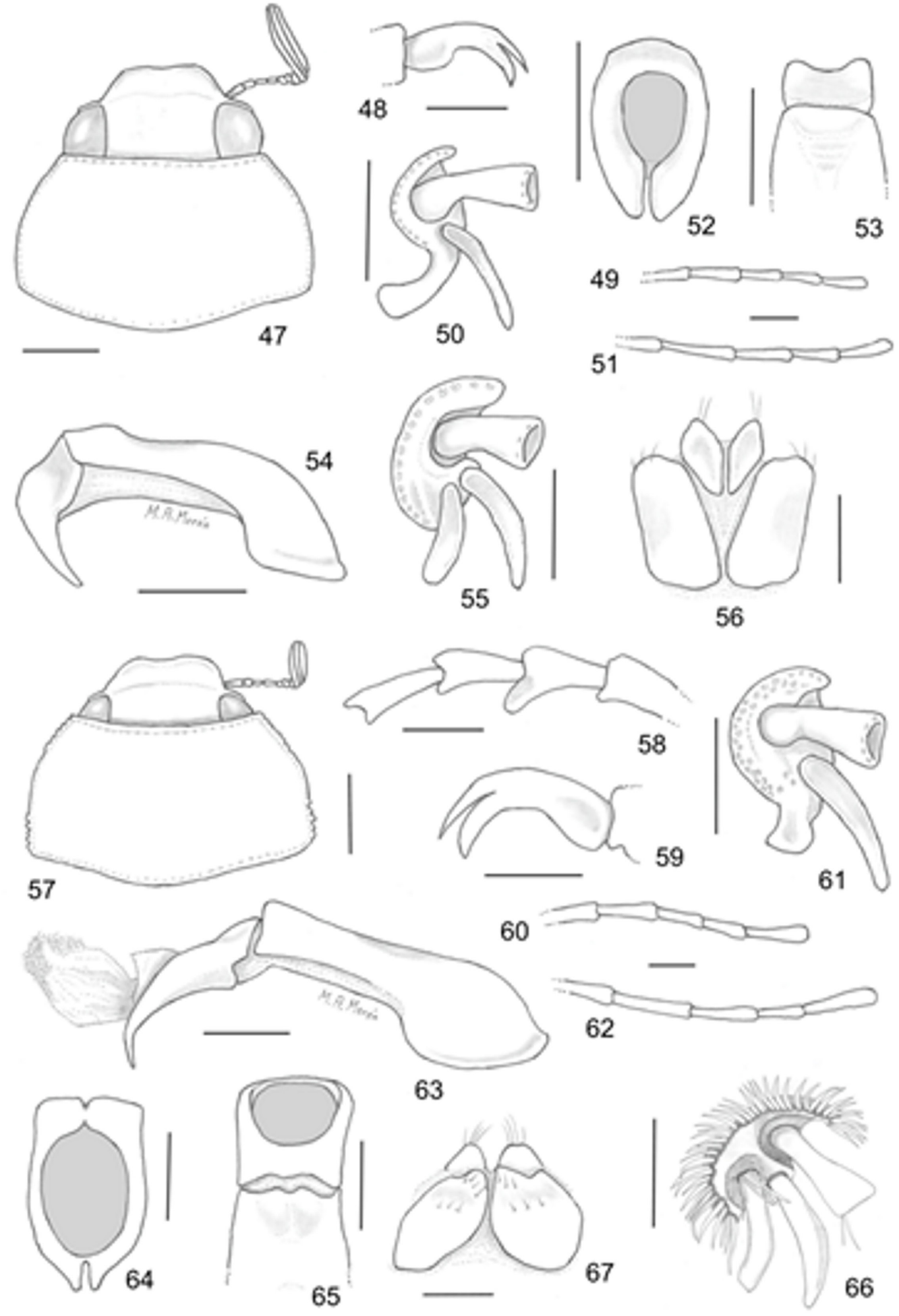

Figuras 47-56. Phyllophaga yautepecana, macho de Yautepec, Oaxaca: 47) Cabeza y pronoto. 48) Uña protarsal externa. 49) Mesotarsómeros. 50) Ápice de la metatibia, distal. 51) Metatarsómeros. 52) Parámeros, distal. 53) Falobase. 54) Parámeros y pieza basal, lateral. Hembra de Yautepec: 55) Ápice de la metatibia, distal. 56) Placas genitales, ventral. Figuras 57-67. Phyllophaga hoogstraali, macho de Chiautla, Puebla: 57) Cabeza y pronoto. 58) Segundo a cuarto protarsómeros. 59) Uña protarsal externa. 60) Mesotarsómeros. 61) Ápice de la metatibia, distal. 62) Metatarsómeros. 63) Cápsula genital completa, lateral. 64) Parámeros, distal. 65) Falobase. Hembra de Barra Potosí, Guerrero: 66) Ápice de la metatibia, distal. Hembra de Tepoztlán, Morelos: 67) Placas genitales, ventral. Líneas de escala $=1 \mathrm{~mm}$, excepto figs. 47, $57=2 \mathrm{~mm}$, figs. $48,59=0.5 \mathrm{~mm}$. 

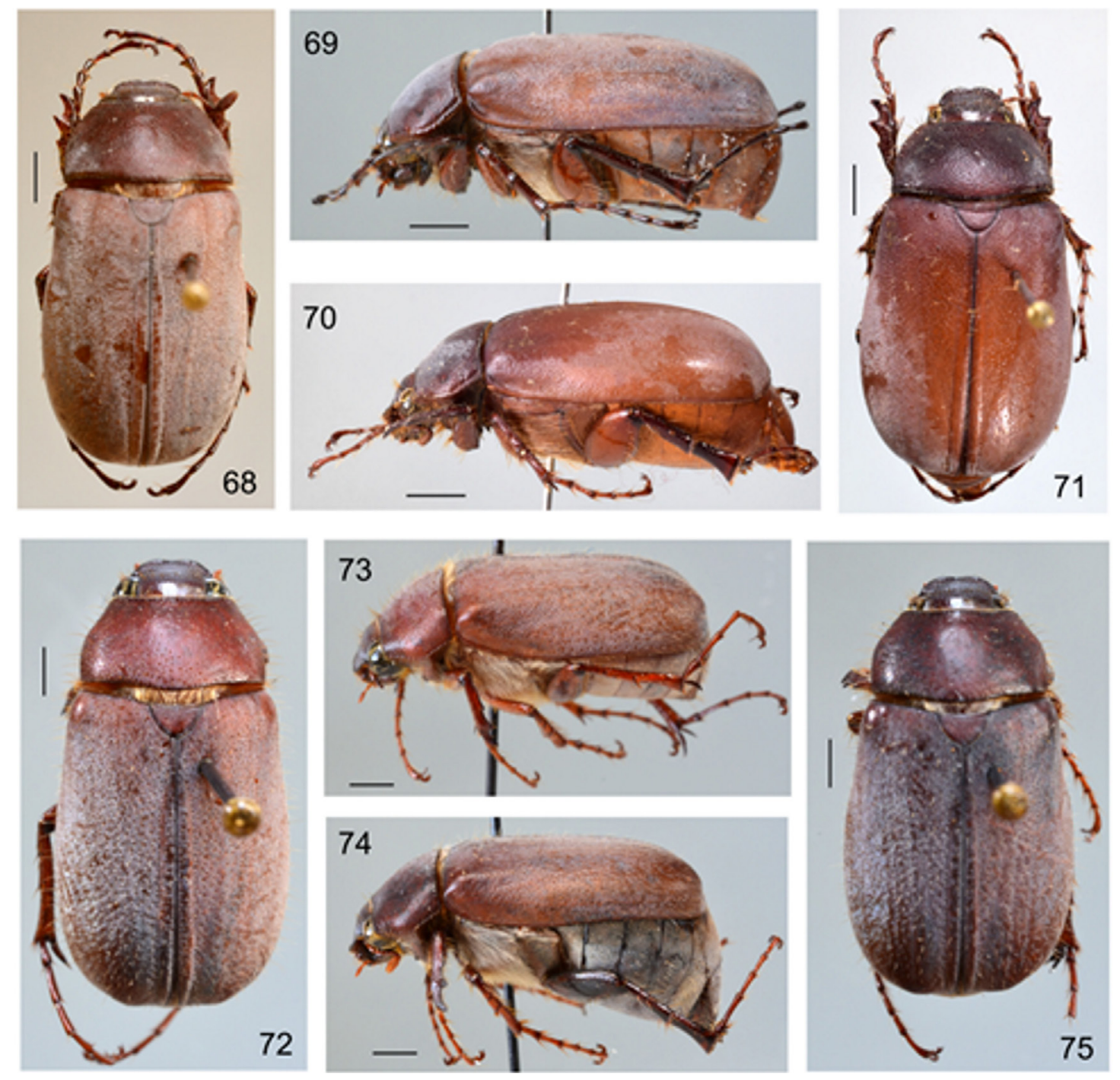

Figuras 68-75. Phyllophaga hoogstraali, macho de Chiautla, Puebla: 68) Vista dorsal. 69) Lateral. Hembra de Zacatepec, Morelos: 70) Lateral. 71) Dorsal. Figuras 72-75. Phyllophaga tegulicollis, macho de Chiapa de Corzo, Chiapas: 72) Dorsal. 73) Lateral. Hembra de Chiapa de Corzo: 74) Lateral. 75) Dorsal. Líneas de escala $=2 \mathrm{~mm}$. 

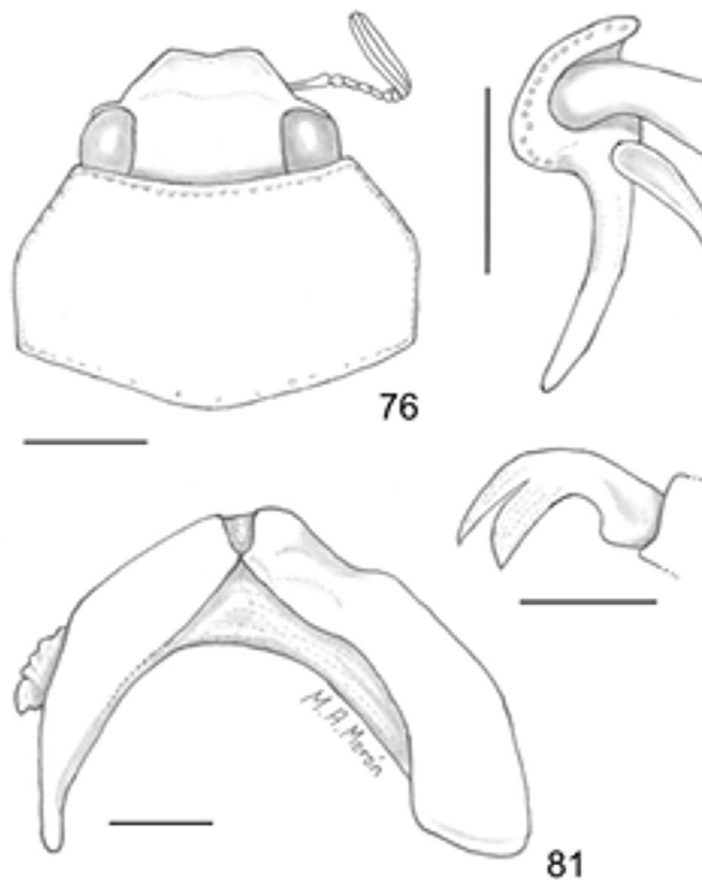

81
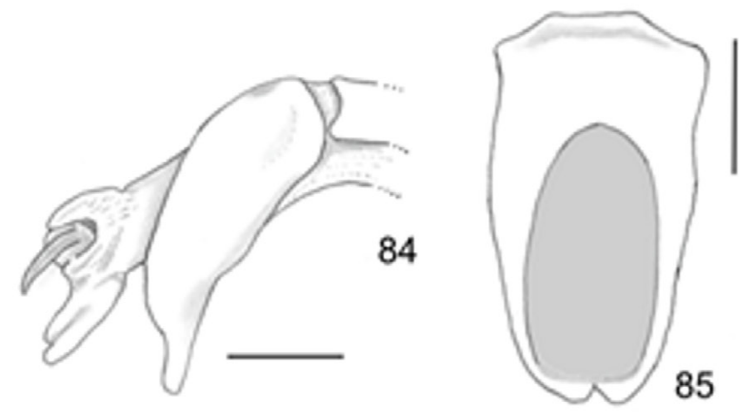

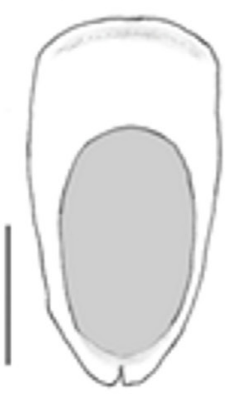

79

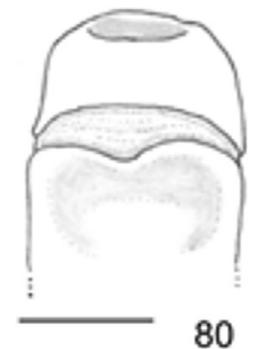

78

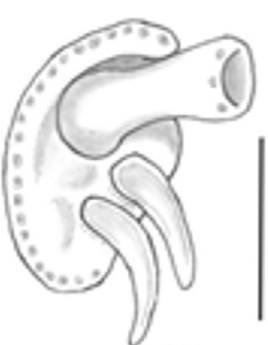

82

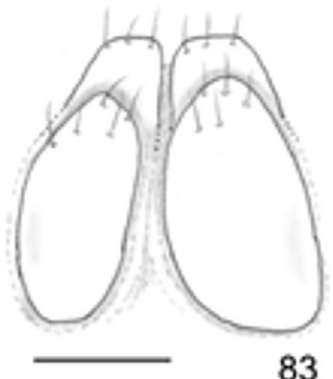

83

Figuras 76-86. Phyllophaga tegulicolis, macho de Chiapa de Corzo, Chiapas: 76) Cabeza y pronoto. 77) Ápice de la metatibia, distal. 78) Uña protarsal externa. 79) Parámeros, distal. 80) Falobase. 81) Parámeros y pieza basal, lateral. Hembra de Chiapa de Corzo: 82) Ápice de la metatibia, distal. 83) Placas genitales, ventral. Holotipo macho de Tegucigalpa, Honduras: 84) Parámeros y saco interno parcialmente expuesto, lateral. Macho de Morazán, Honduras: 85) Parámeros, distal. 86) Parámeros y pieza basal, lateral. Líneas de escala $=1 \mathrm{~mm}$, excepto fig. $76=2 \mathrm{~mm}$, fig. $78=0.5 \mathrm{~mm}$. 

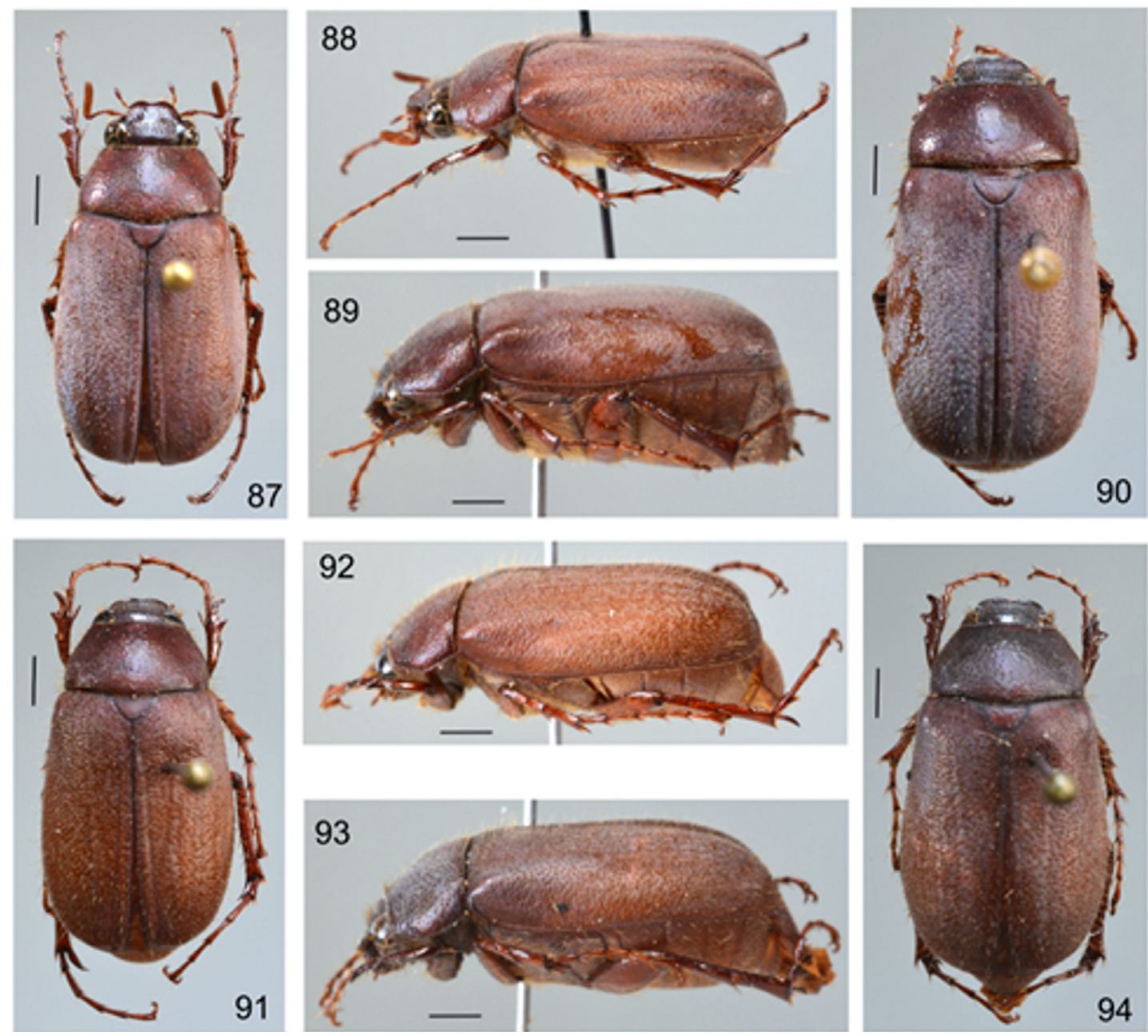

Figuras 87-94. Phyllophaga tegenara, macho de Santa Rosa, Guanacaste, Costa Rica: 87) Vista dorsal. 88) Lateral. Hembra de Santa Rosa: 89) Lateral. 90) Dorsal. Macho de Domitila, Granada, Nicaragua: 91) Dorsal. 92) Lateral. Hembra de Domitila: 93) Lateral. 94) Dorsal. Líneas de escala $=2 \mathrm{~mm}$. 

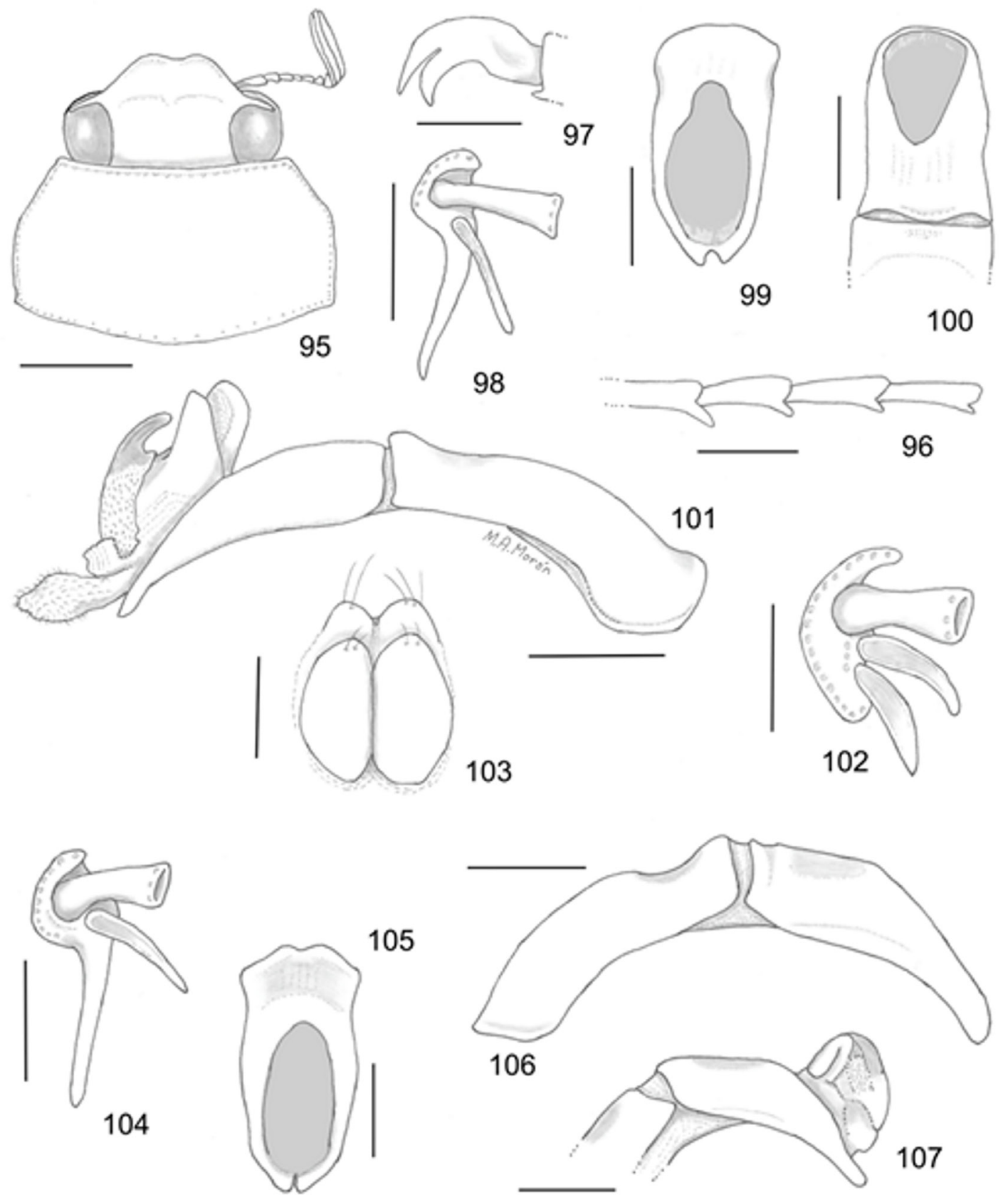

Figuras 95-107. Phyllophaga tegenara, macho de Santa Rosa, Guanacaste: 95) Cabeza y pronoto. 96) Protarsómeros. 97) Uña protarsal externa. 98) Ápice de la metatibia, distal. 99) Parámeros, distal. 100) Falobase. 101) Cápsula genital completa con saco interno extendido, lateral. Hembra de Santa Rosa: 102) Ápice de la metatibia, distal. 103) Placas genitales, ventral. Macho de Domitila, Granada: 104) Ápice de la metatibia, distal. 105) Parámeros, distal. 106) Parámeros y pieza basal, lateral. Holotipo macho de Guanacaste: 107) Parámeros y saco interno poco extendido, lateral. Líneas de escala $=1 \mathrm{~mm}$, excepto fig. $95=2 \mathrm{~mm}$, fig. $97=0.5 \mathrm{~mm}$. 


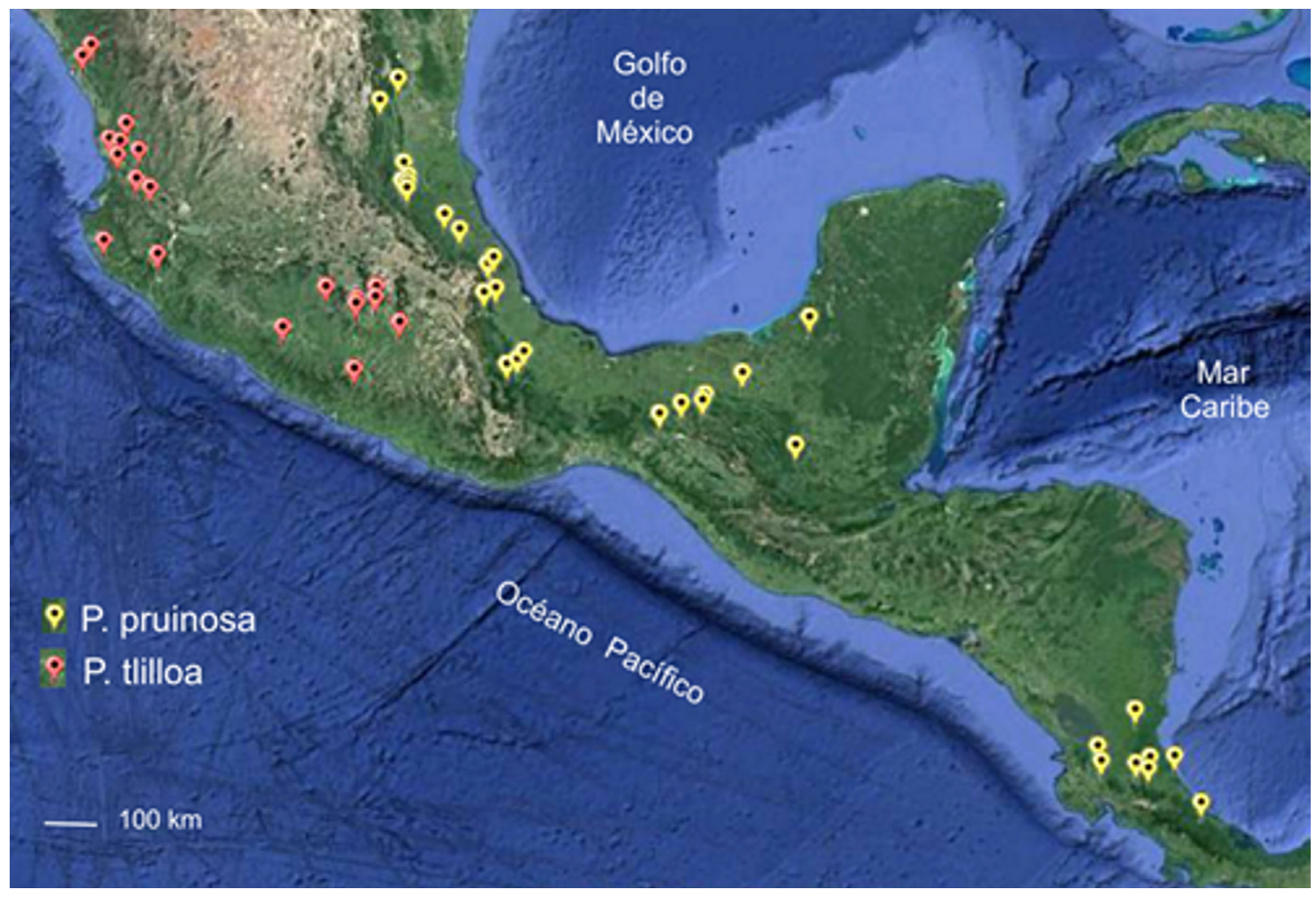

Figura 108. Distribución de Phyllophaga pruinosa y P. tlilloa. Mapa base modificado de Google Earth, 13/12/2015.

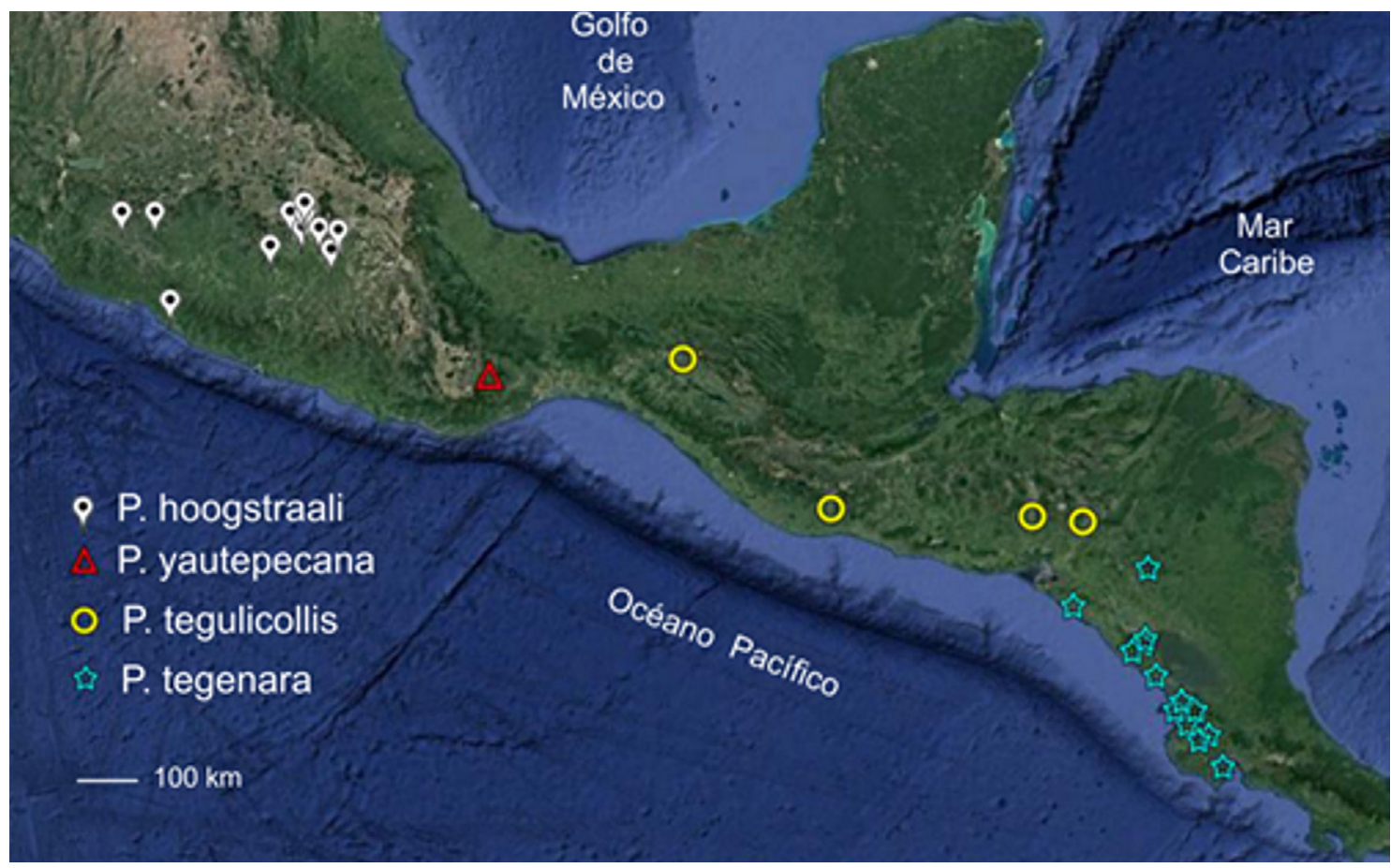

Figura 109. Distribución de Phyllophaga hoogstraali, P. yautepecana, P. tegulicolis y P. tegenara. Mapa base modificado de Google Earth, 13/12/2015. 